\title{
A Modular Formal Total Synthesis of
}

\section{(士)-Cycloclavine}

Natalie Netz and Till Opatz*

Institute of Organic Chemistry, University of Mainz, Duesbergweg 10-14, D-55128

Mainz, Germany

E-mail: opatz@uni-mainz.de

Supporting Information

\section{Contents}

Contents

Spectra 


\section{Spectra}
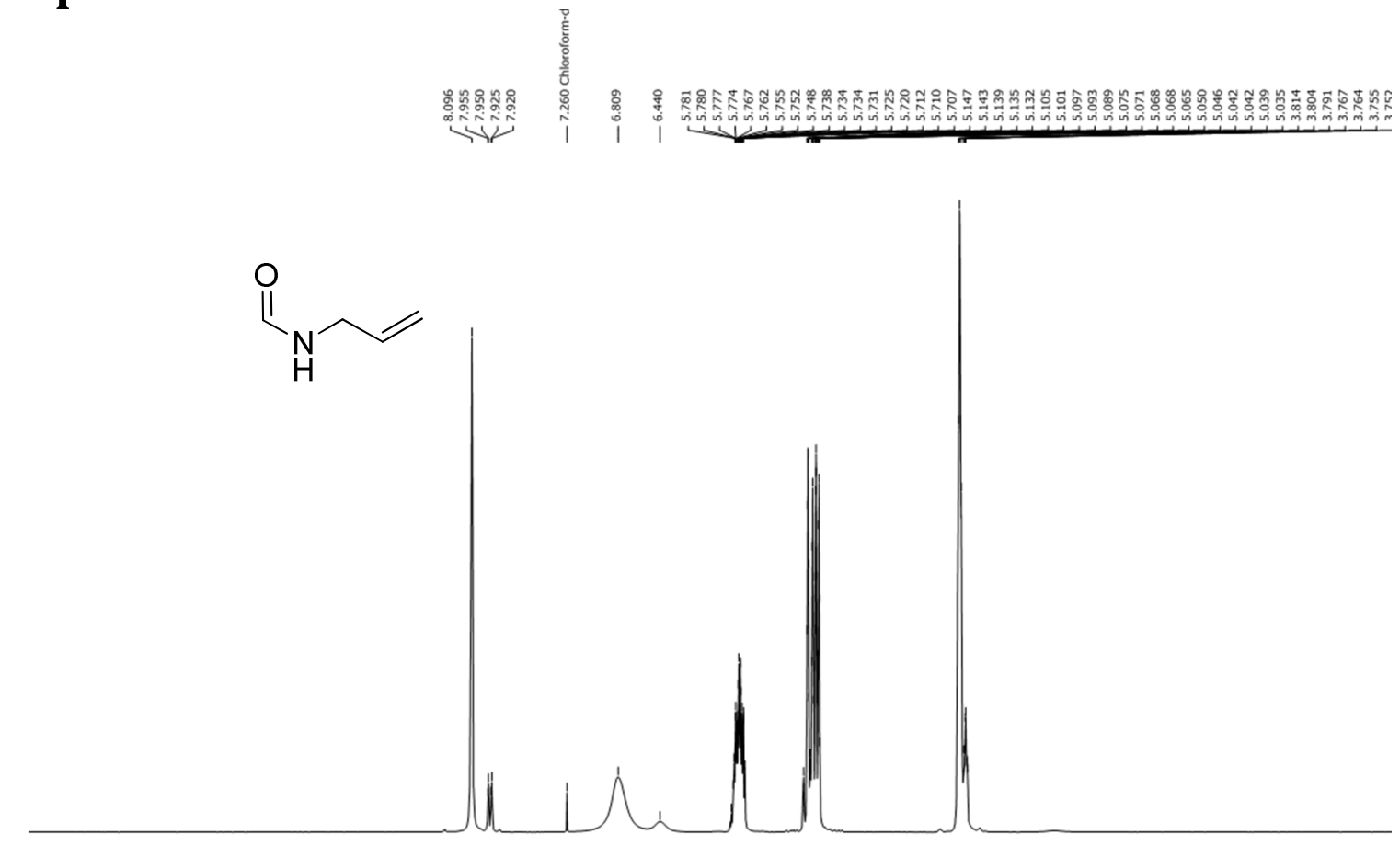

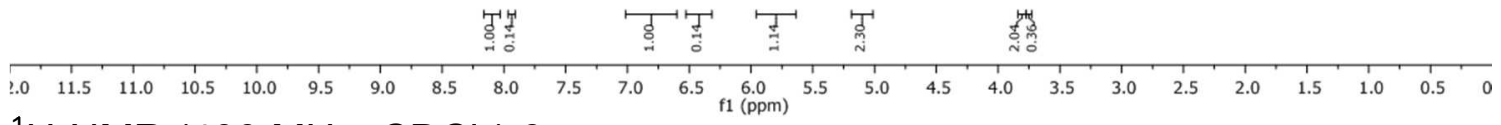

${ }^{1} \mathrm{H}-\mathrm{NMR}\left(400 \mathrm{MHz}^{\mathrm{CDCl}} \mathrm{CDC}_{3} \mathbf{6}\right.$

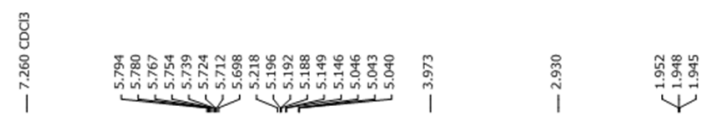<smiles>C=CCN(C)C(=O)C(=C)C</smiles>

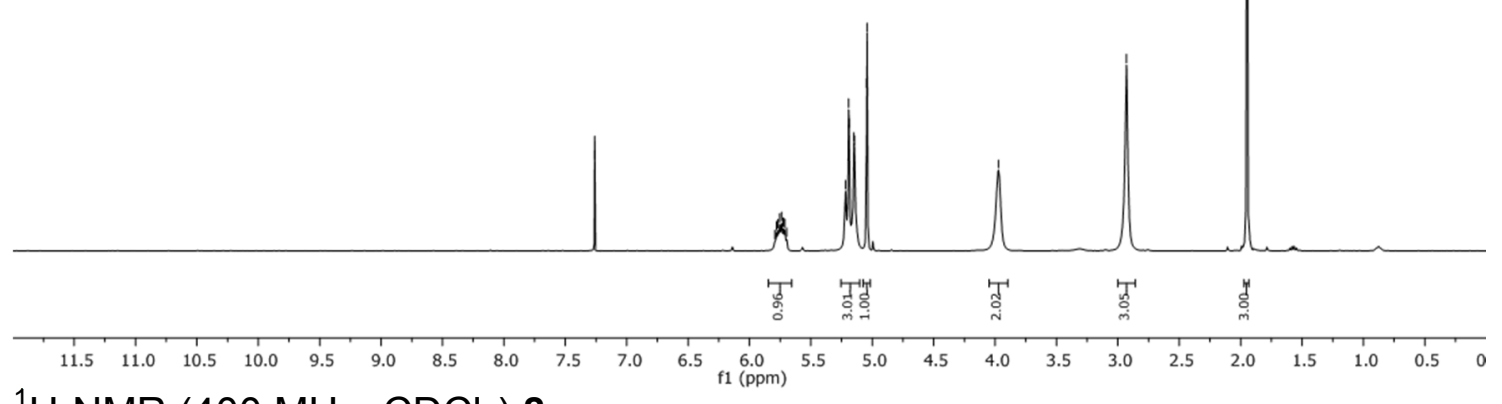

${ }^{1} \mathrm{H}-\mathrm{NMR}\left(400 \mathrm{MHz}, \mathrm{CDCl}_{3}\right) 8$ 

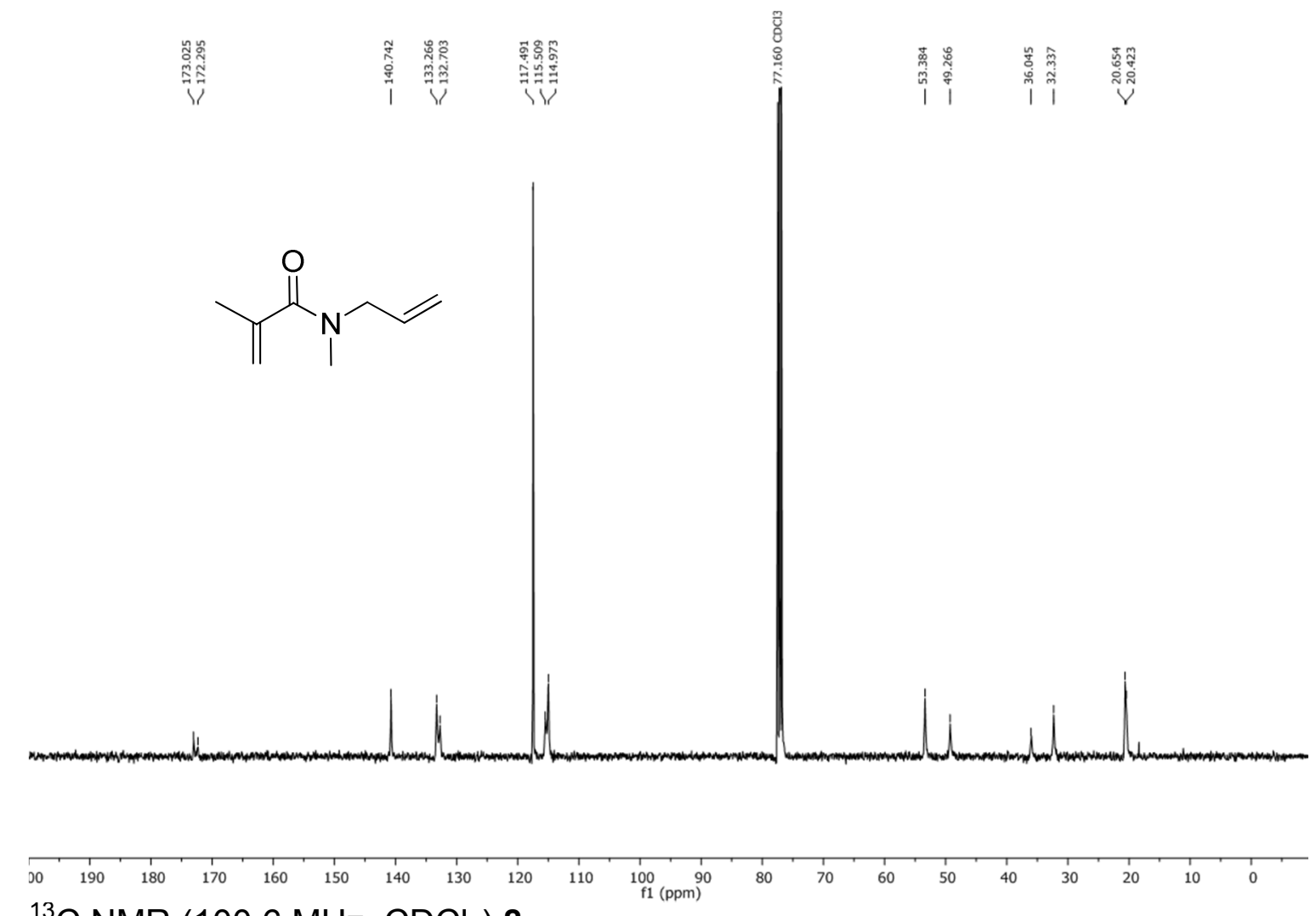

${ }^{13} \mathrm{C}$ NMR $\left(100.6 \mathrm{MHz}, \mathrm{CDCl}_{3}\right) 8$
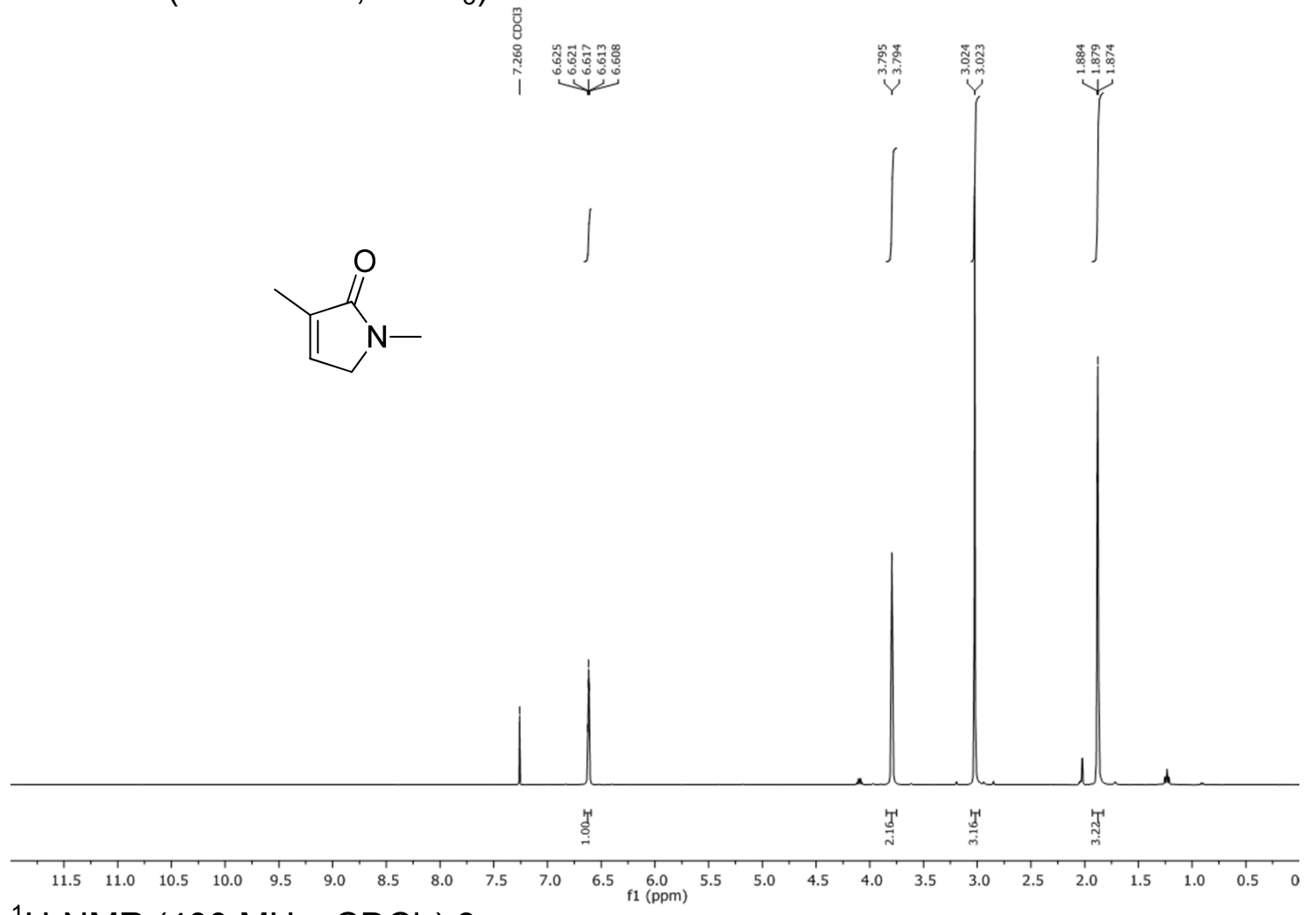

${ }^{1} \mathrm{H}-\mathrm{NMR}\left(400 \mathrm{MHz}, \mathrm{CDCl}_{3}\right) 3$ 

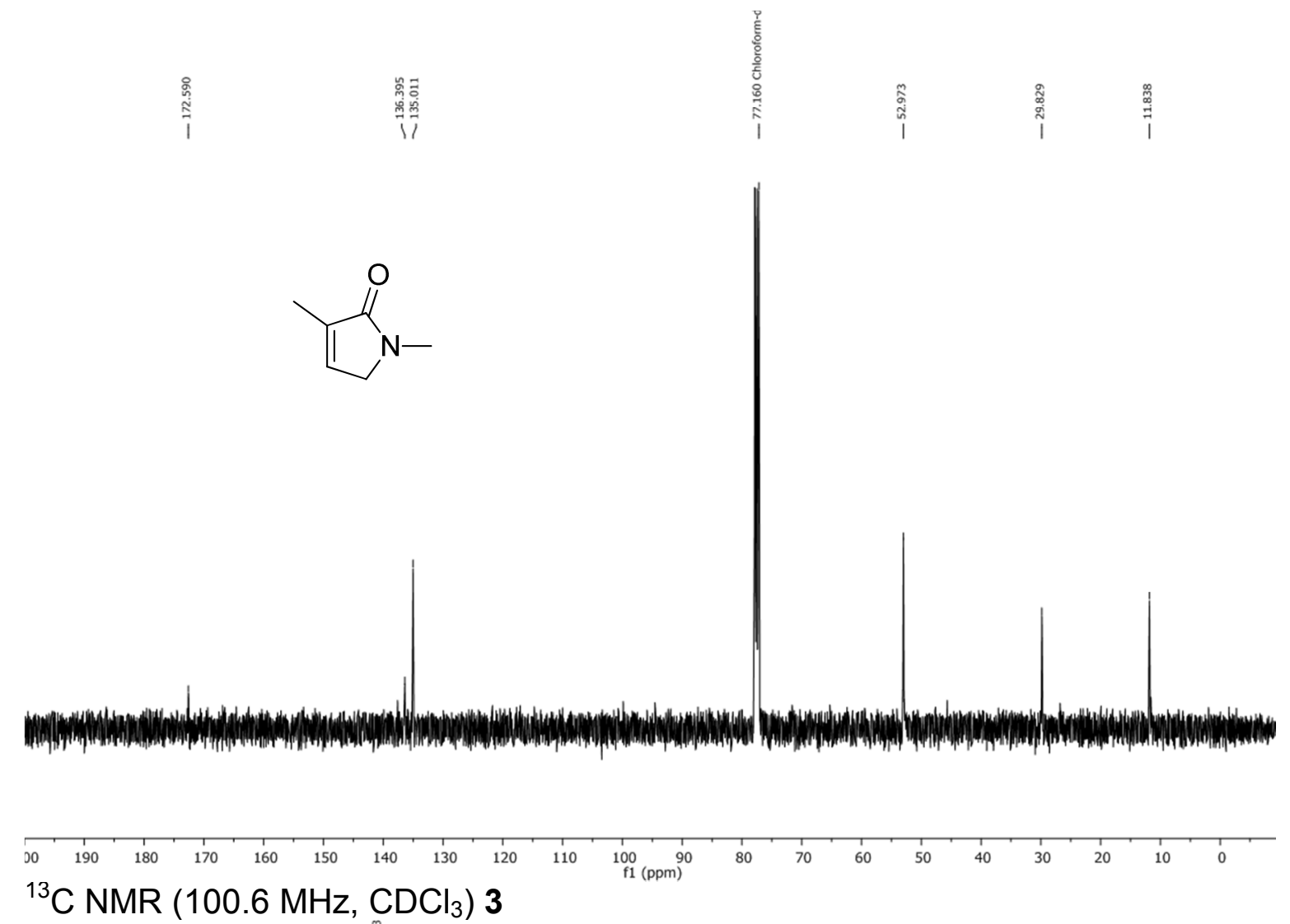

${ }^{13} \mathrm{C}$ NMR (100.6 MHz, $\left.\mathrm{CDCl}_{3}\right) 3$
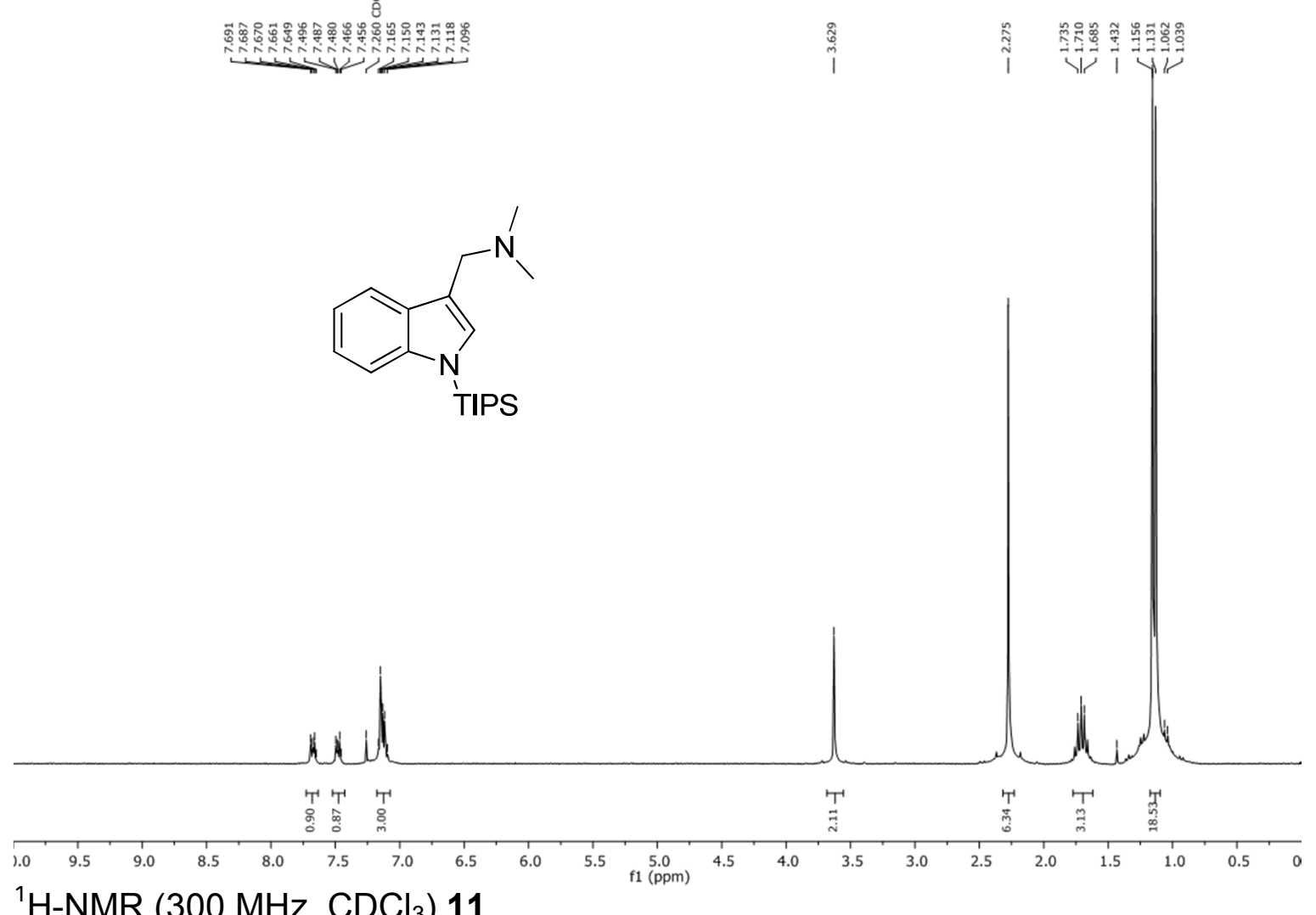

${ }^{1} \mathrm{H}-\mathrm{NMR}\left(300 \mathrm{MHz}, \mathrm{CDCl}_{3}\right) 11$ 


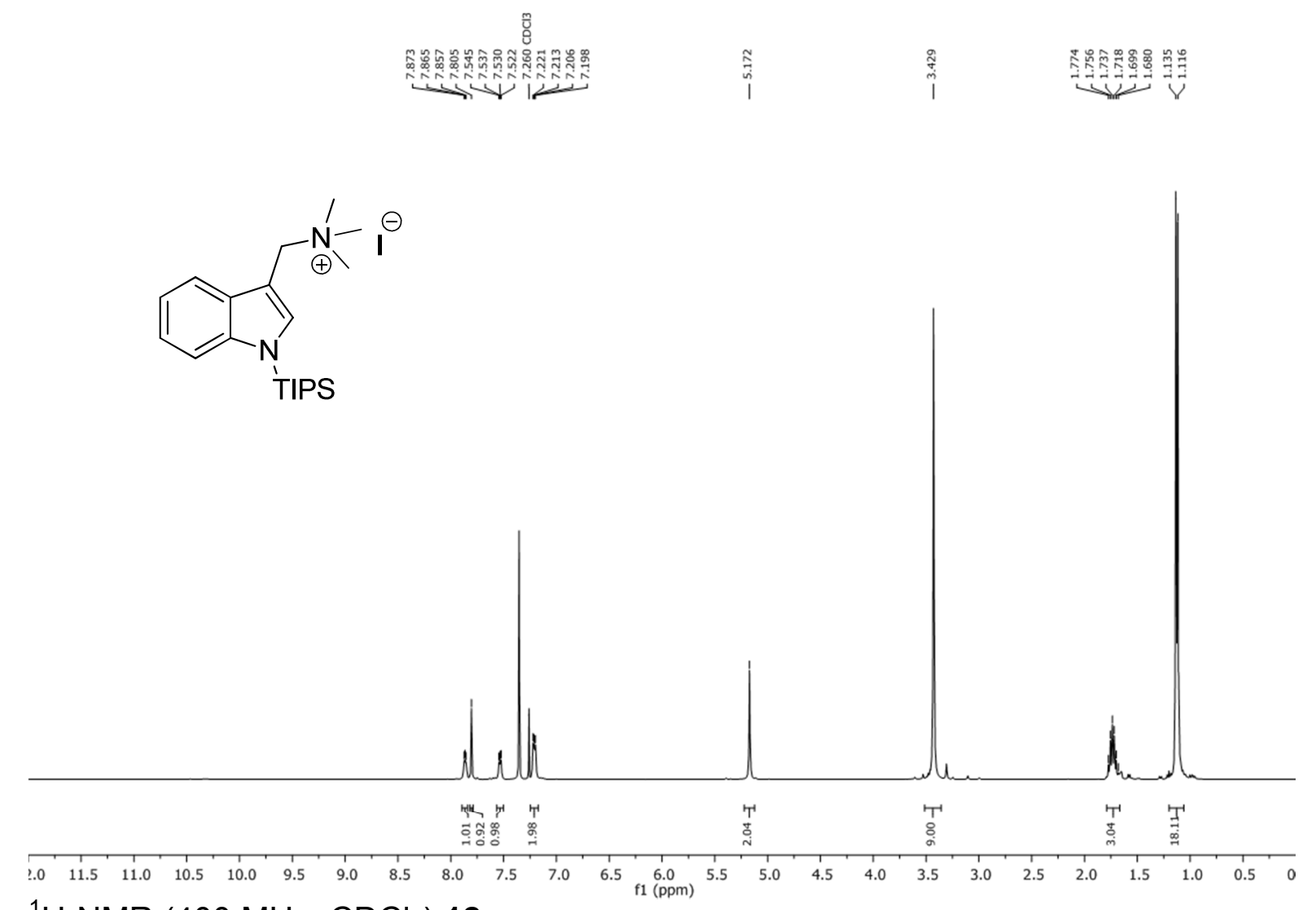

${ }^{1} \mathrm{H}-\mathrm{NMR}\left(400 \mathrm{MHz}, \mathrm{CDCl}_{3}\right) 12$
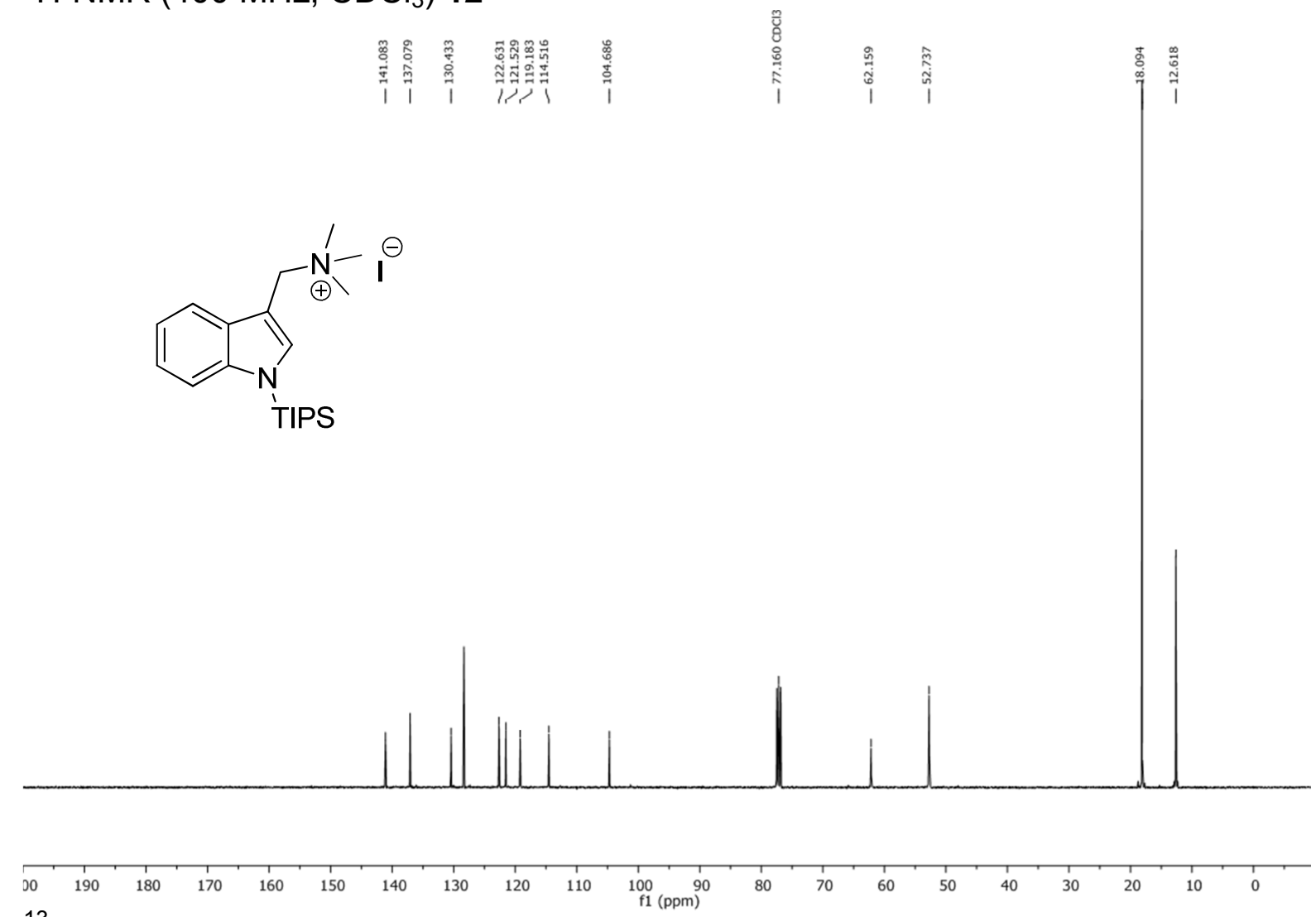
${ }^{13} \mathrm{C}$ NMR (100.6 MHz, $\left.\mathrm{CDCl}_{3}\right) 12$ 


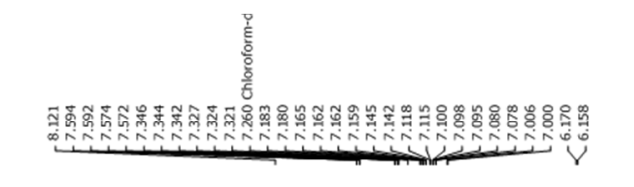

暂

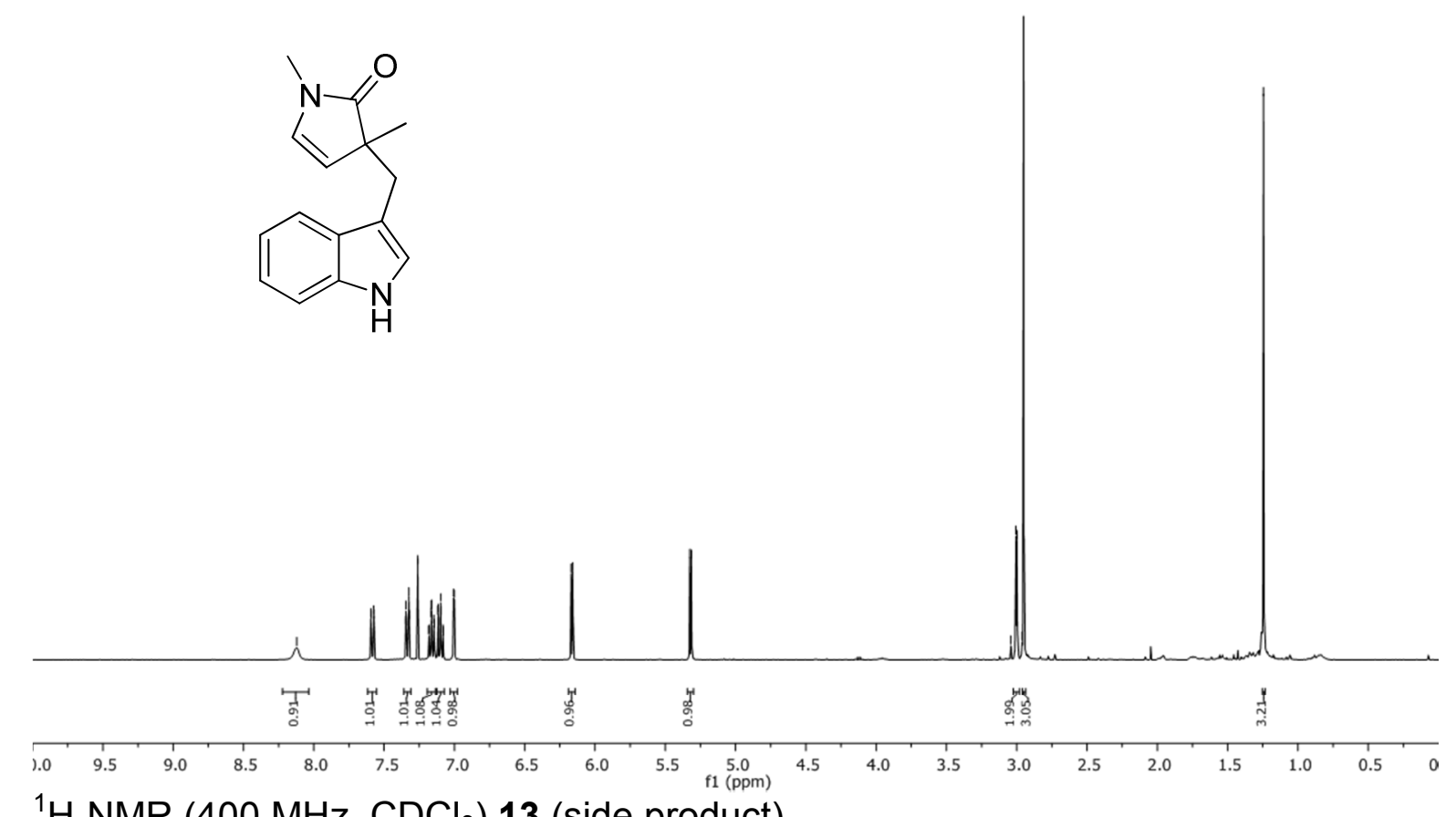

${ }^{1} \mathrm{H}-\mathrm{NMR}\left(400 \mathrm{MHz}, \mathrm{CDCl}_{3}\right) 13$ (side product)

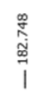

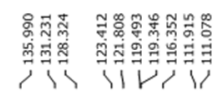

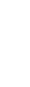




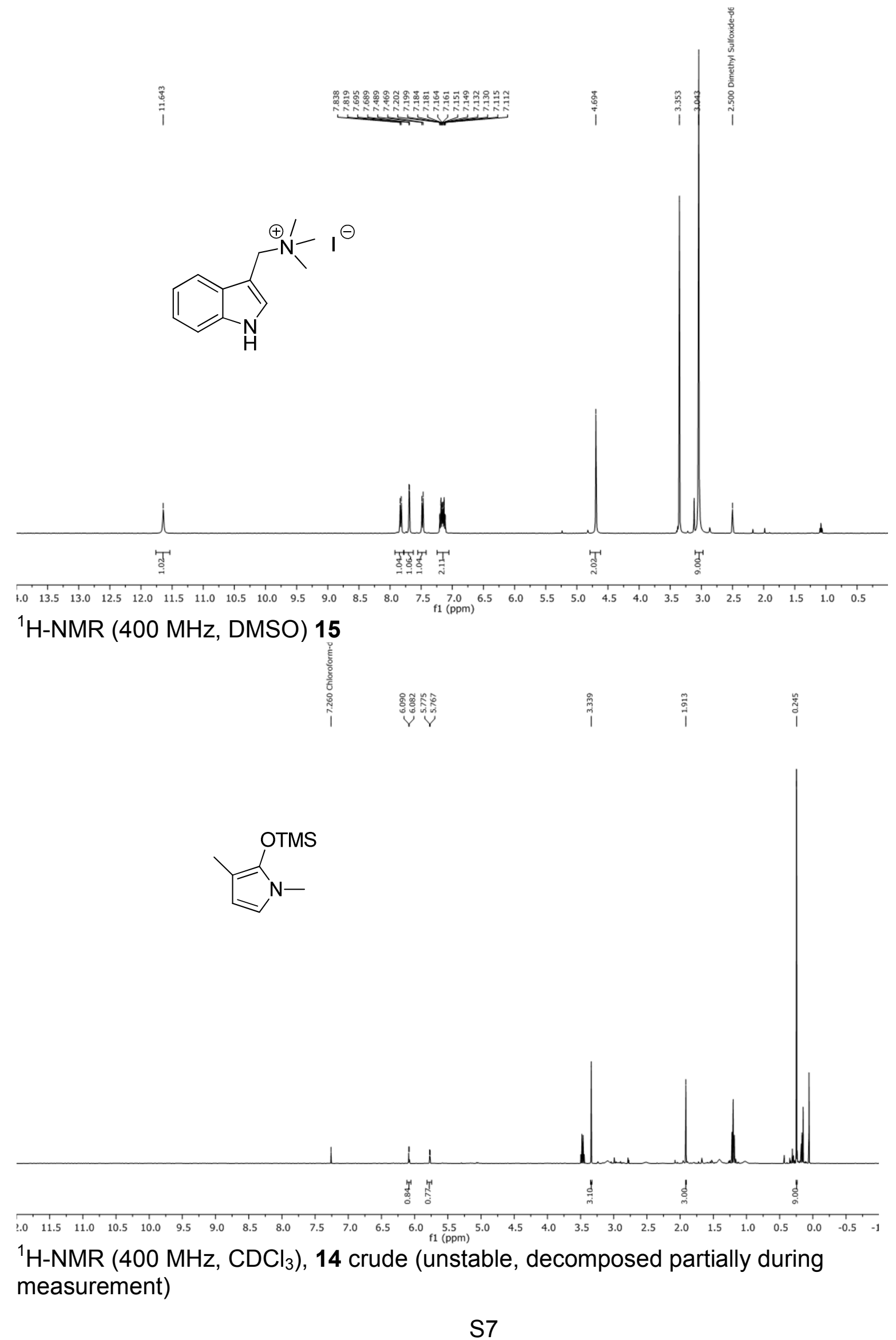



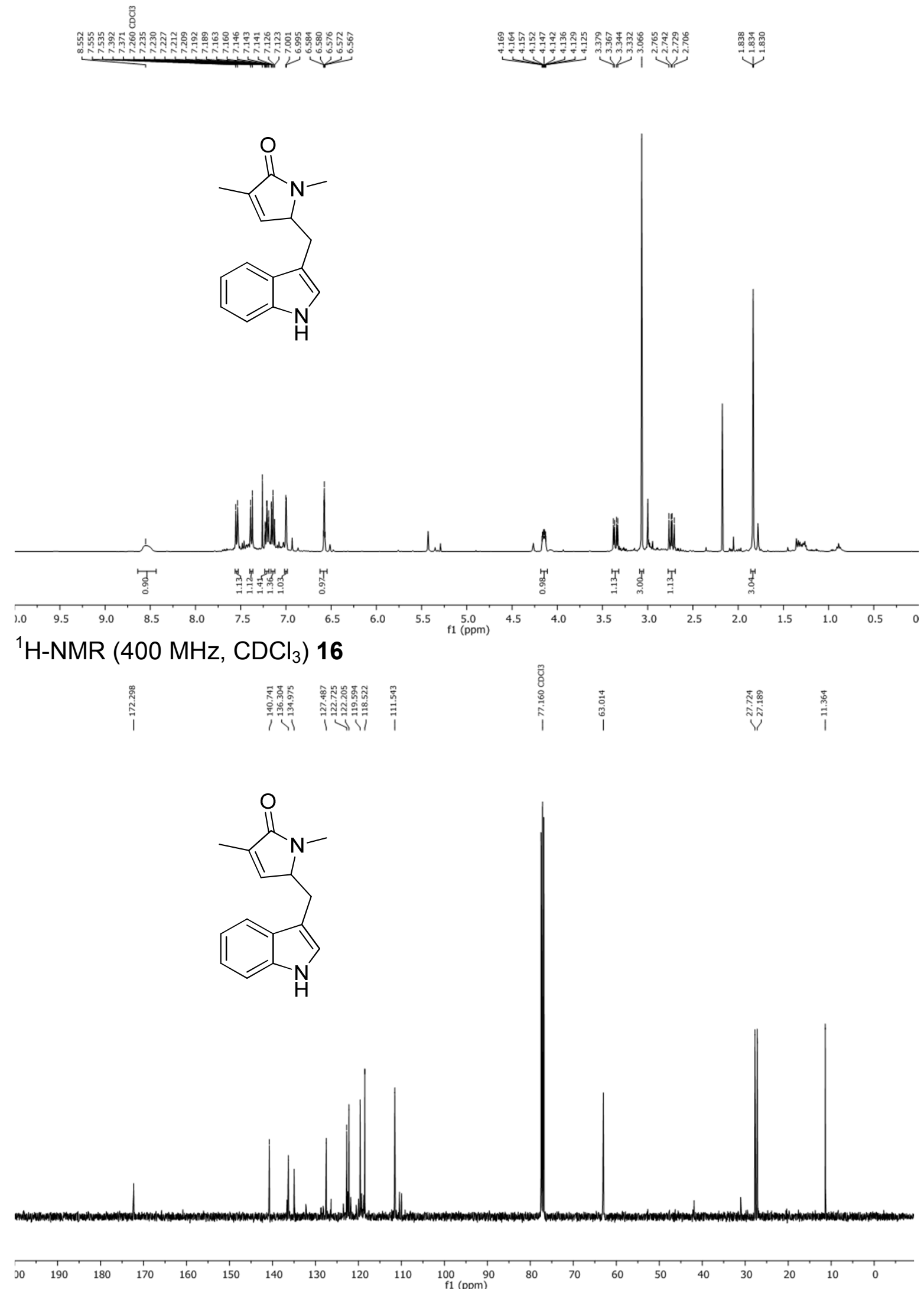

${ }^{13} \mathrm{C}$ NMR $\left(100.6 \mathrm{MHz}, \mathrm{CDCl}_{3}\right) 16$ 

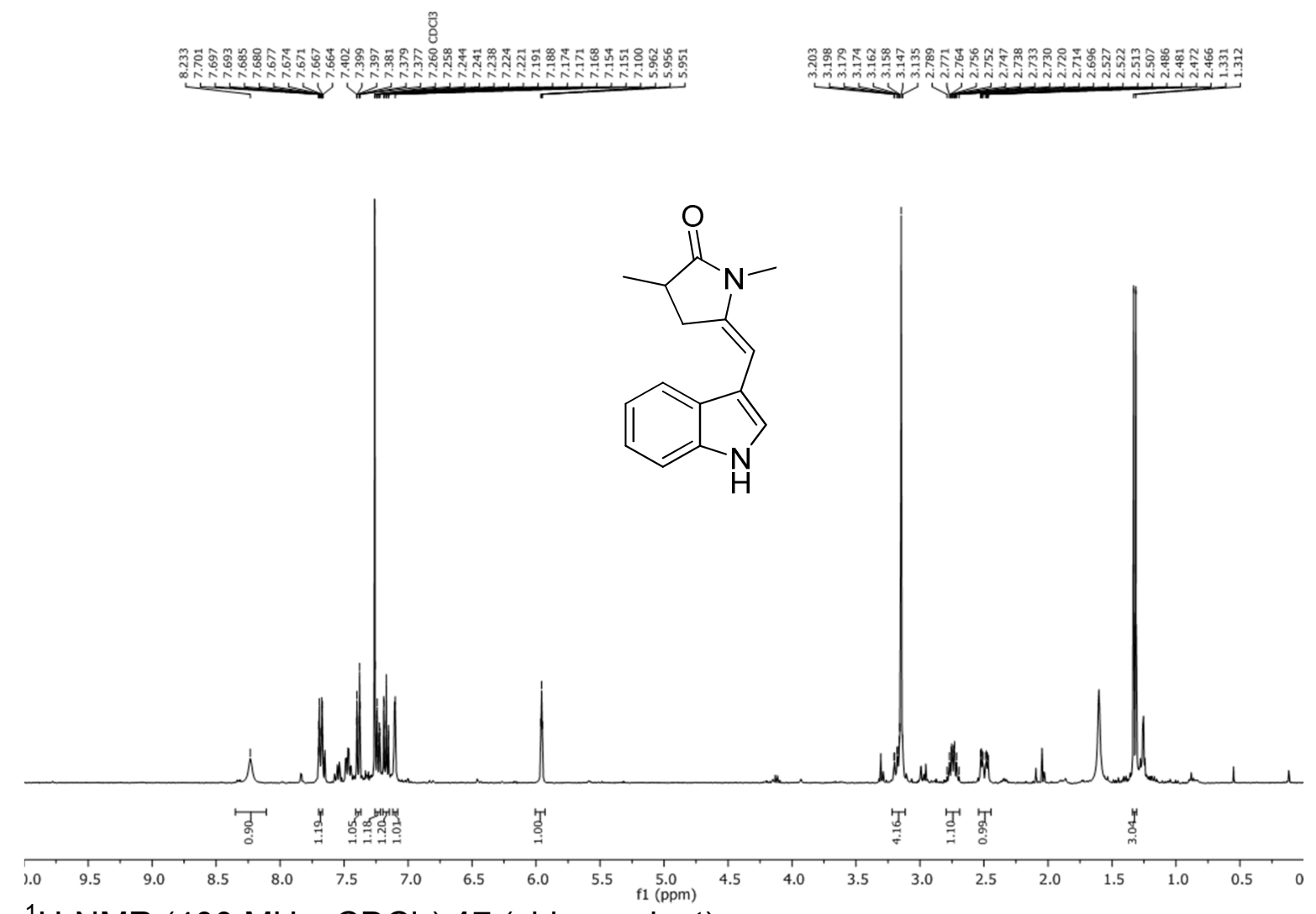

${ }^{1} \mathrm{H}-\mathrm{NMR}\left(400 \mathrm{MHz}, \mathrm{CDCl}_{3}\right) 17$ (side product)
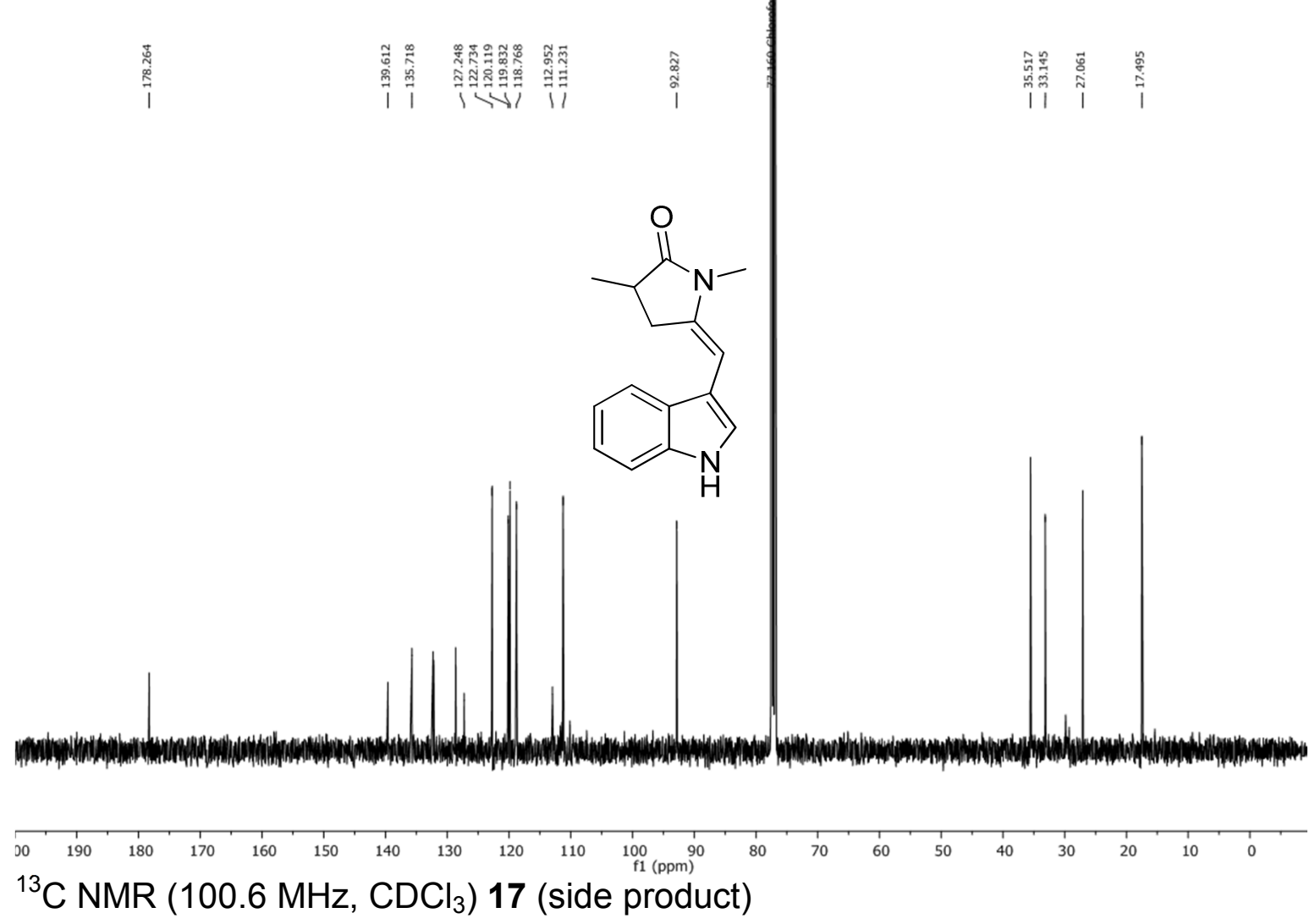


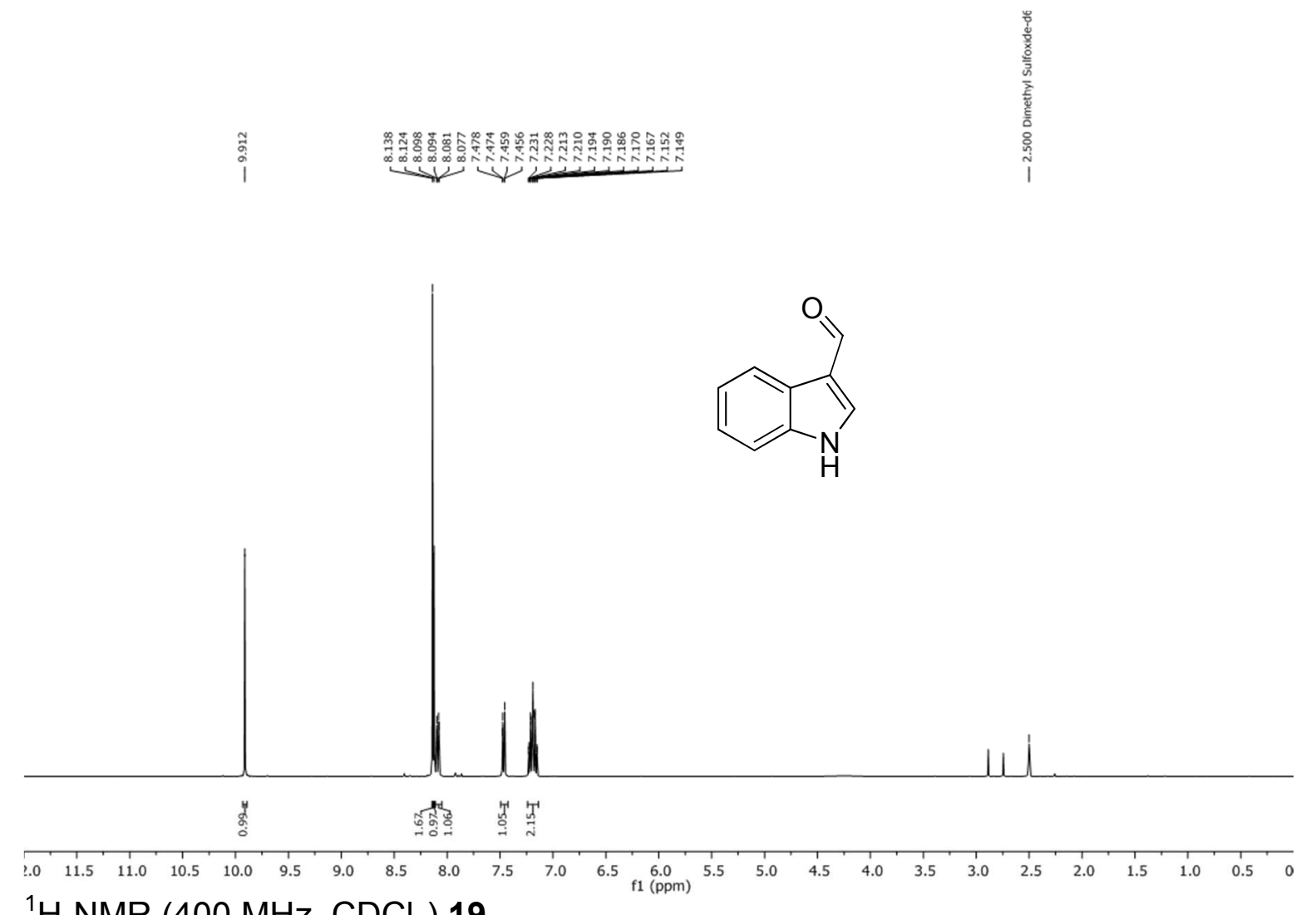

${ }^{1} \mathrm{H}-\mathrm{NMR}\left(400 \mathrm{MHz}, \mathrm{CDCl}_{3}\right) 19$
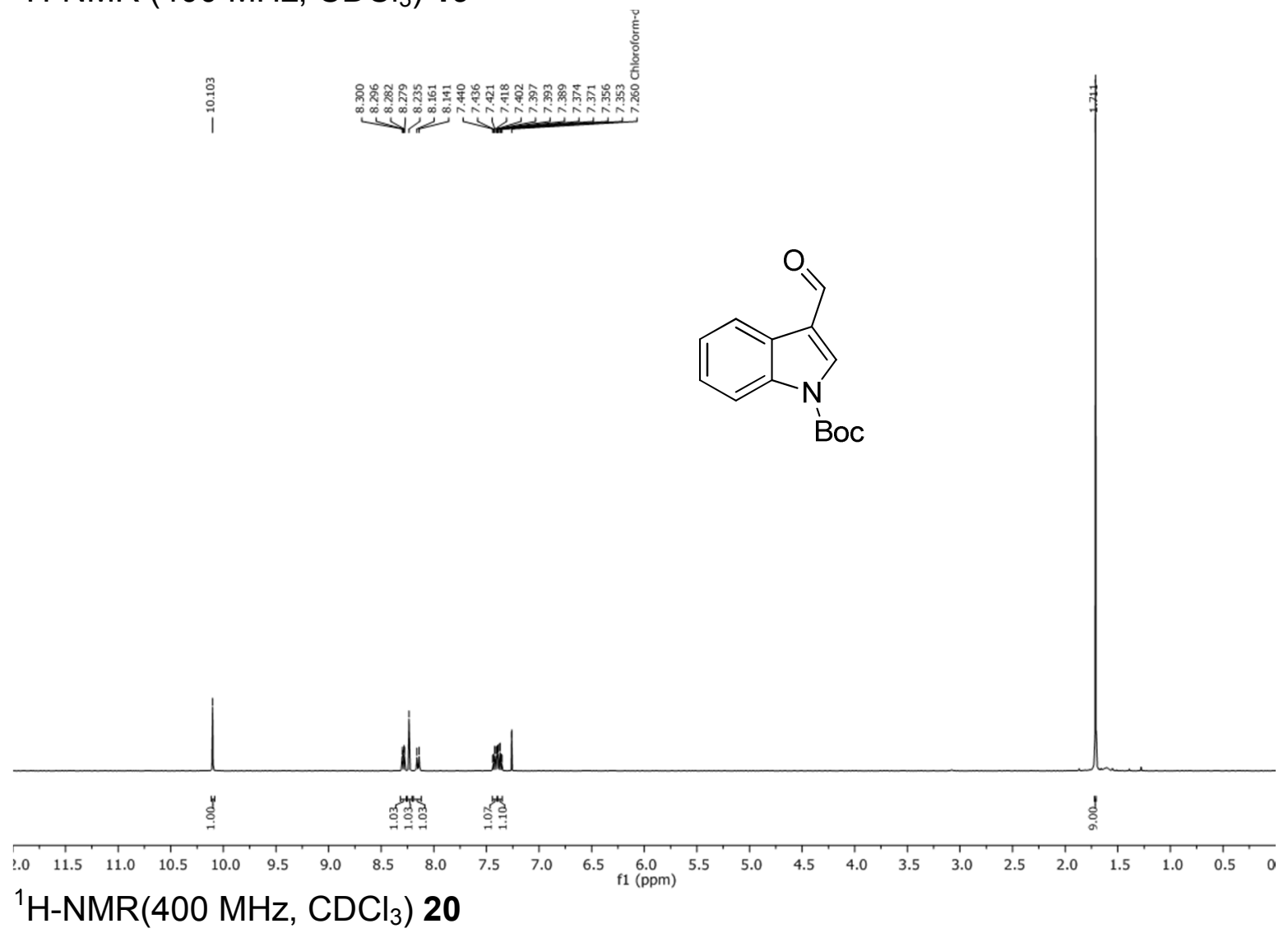

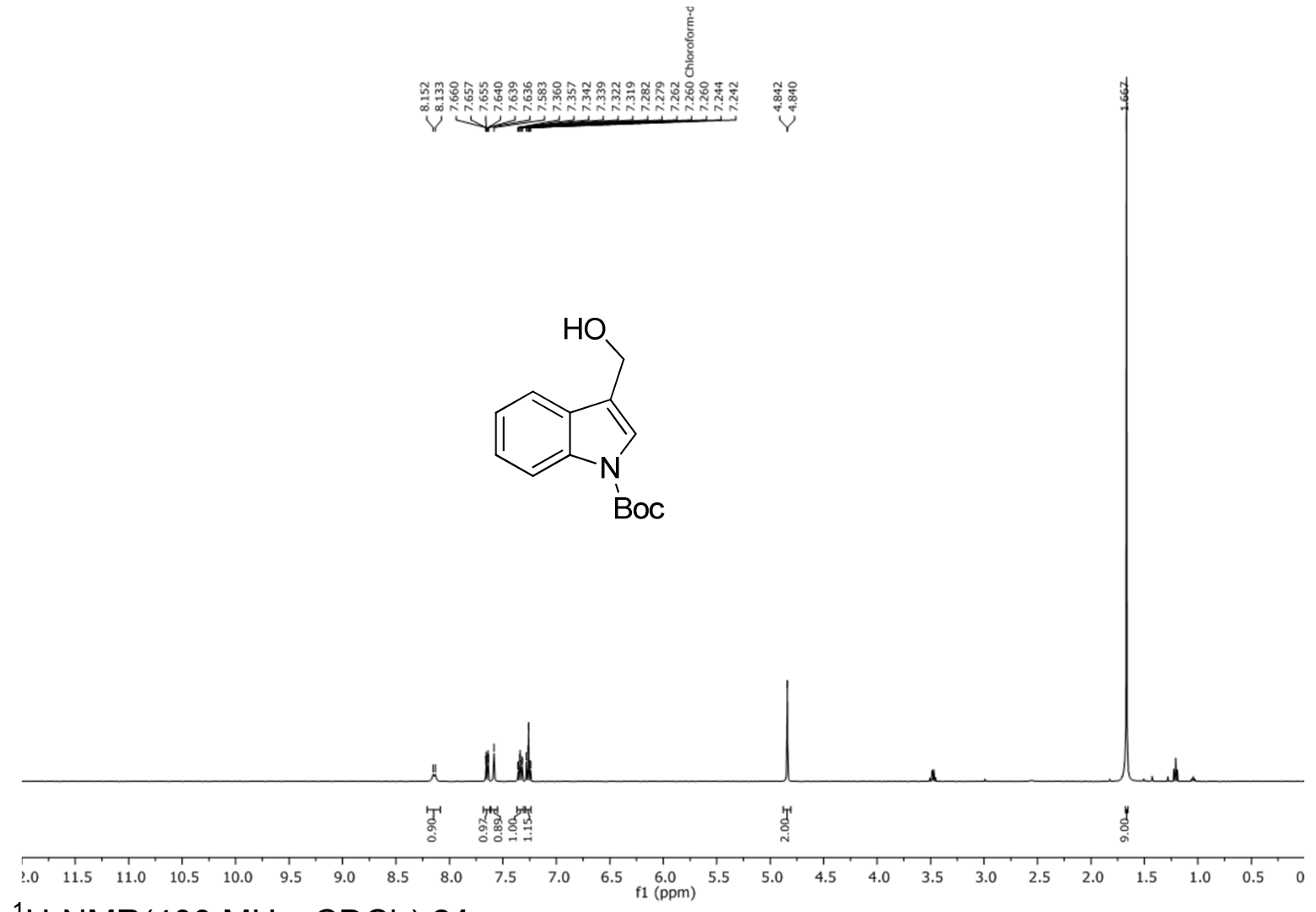

${ }^{1} \mathrm{H}-\mathrm{NMR}\left(400 \mathrm{MHz}, \mathrm{CDCl}_{3}\right) 21$
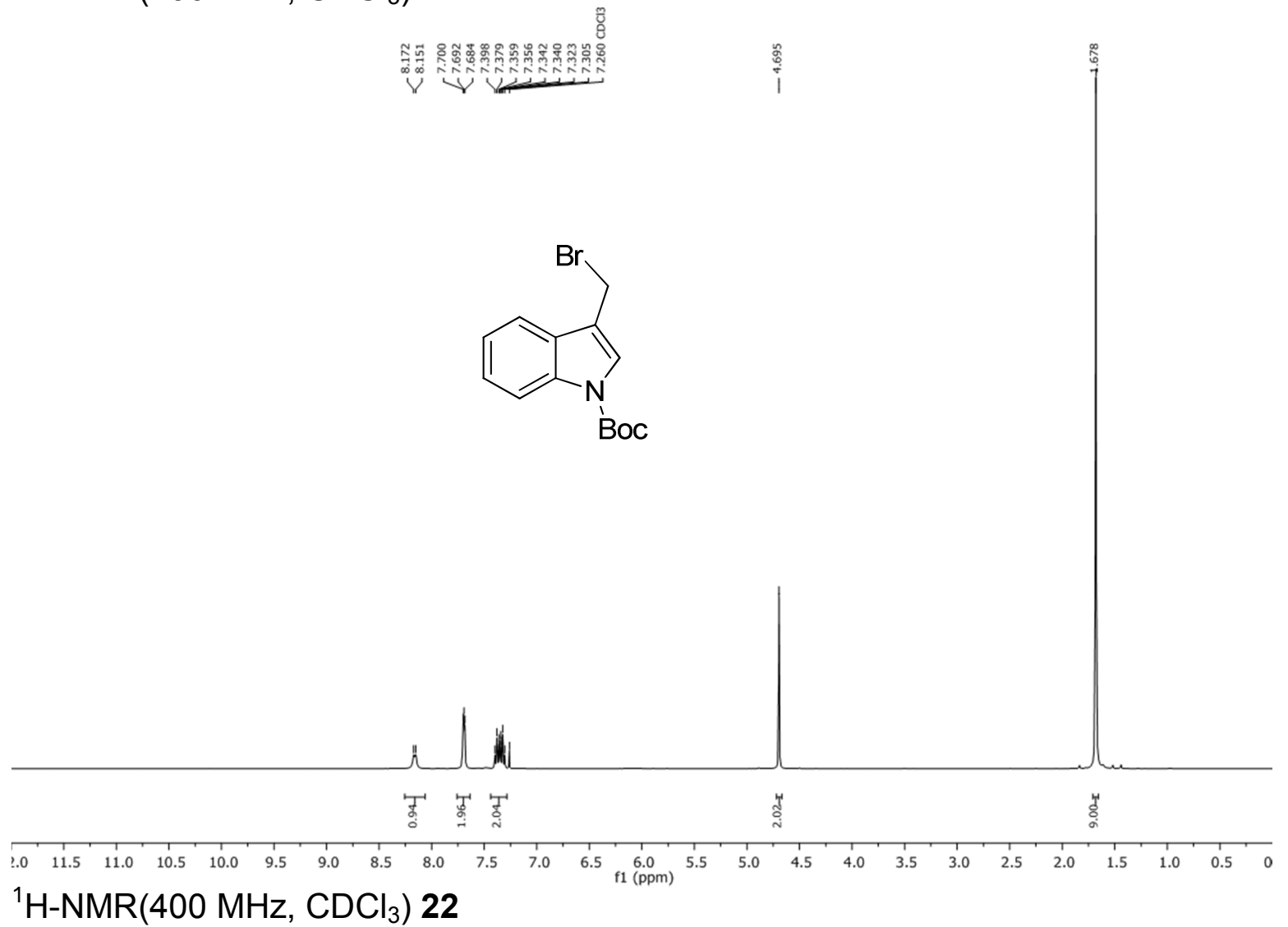

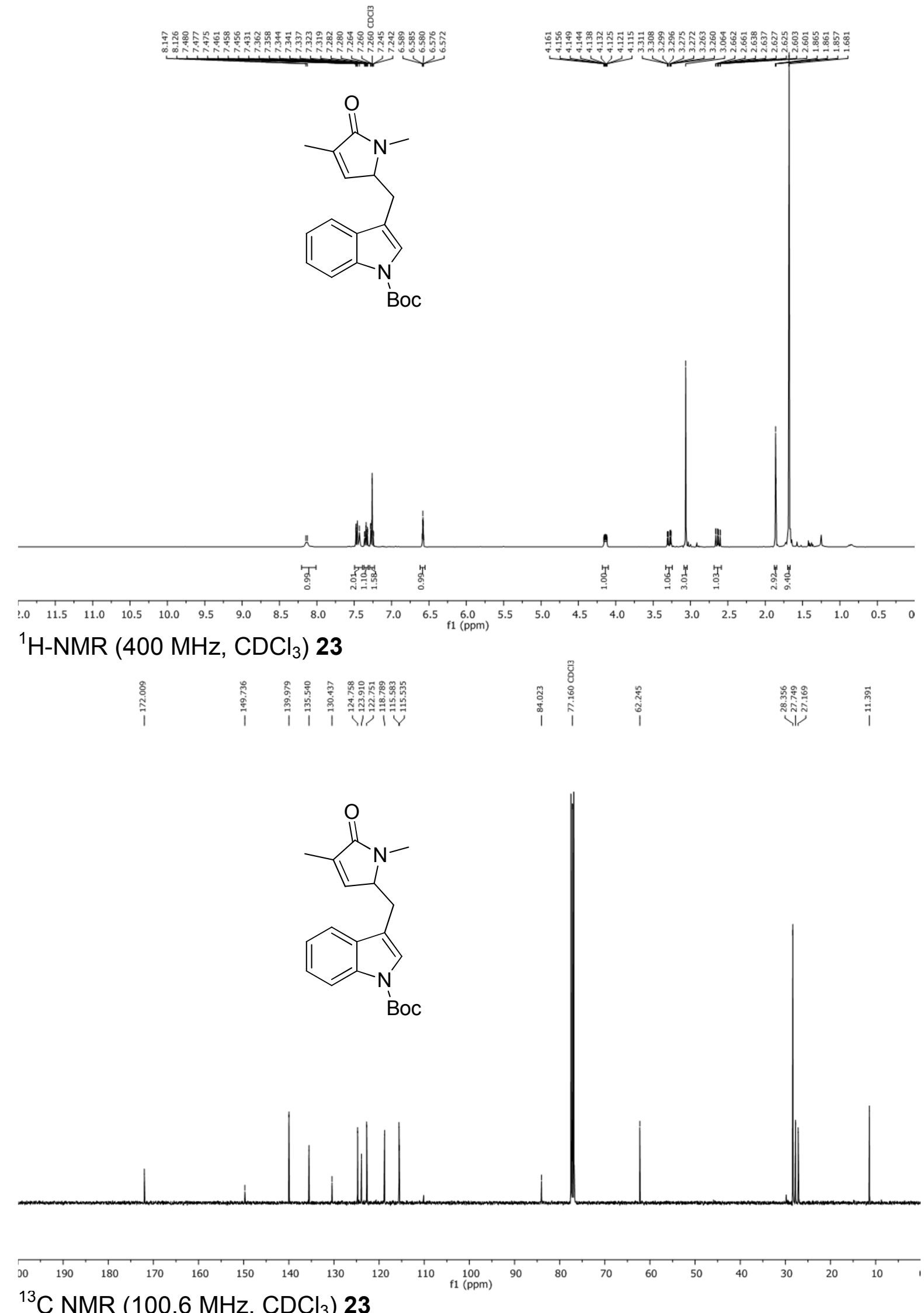

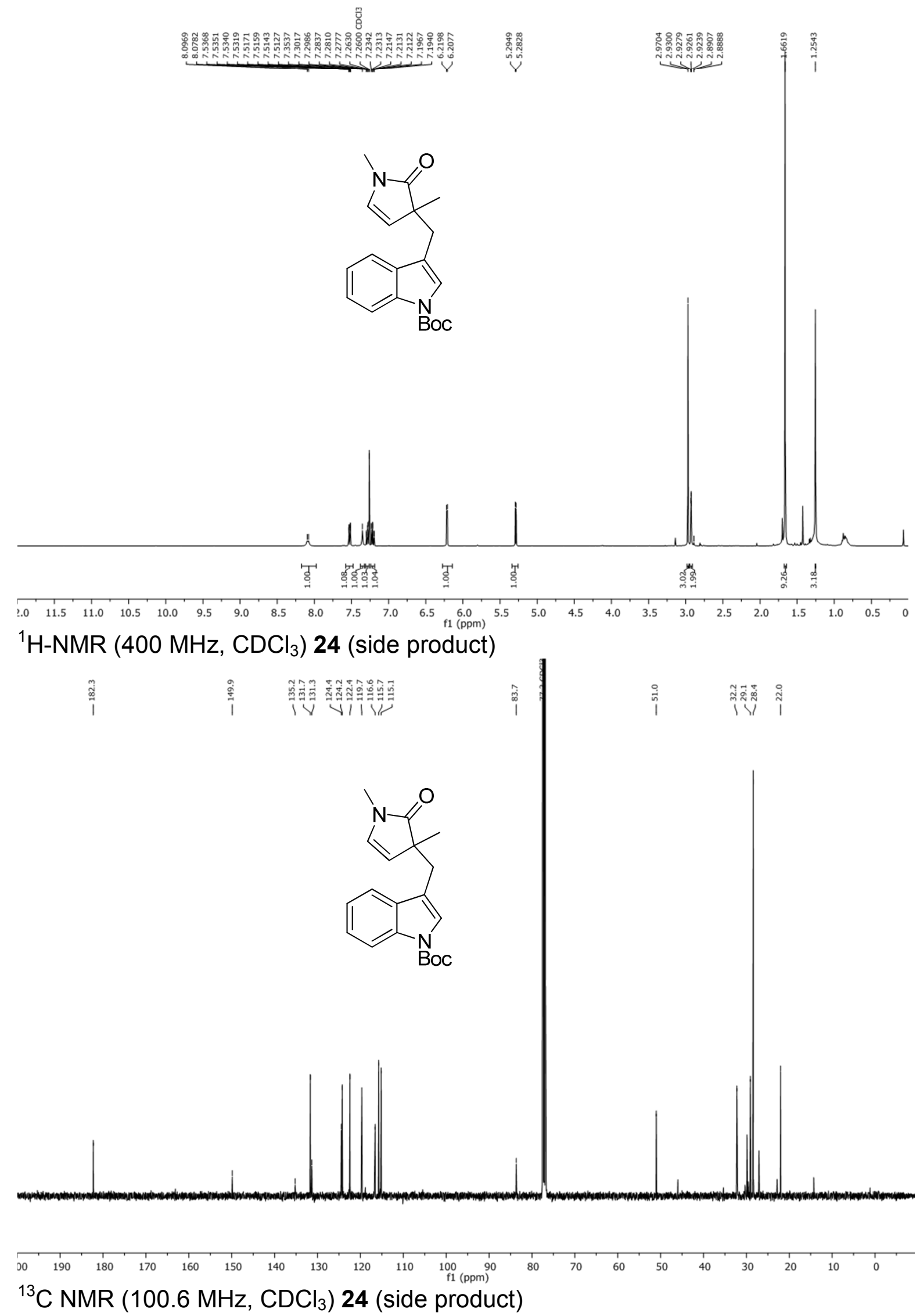

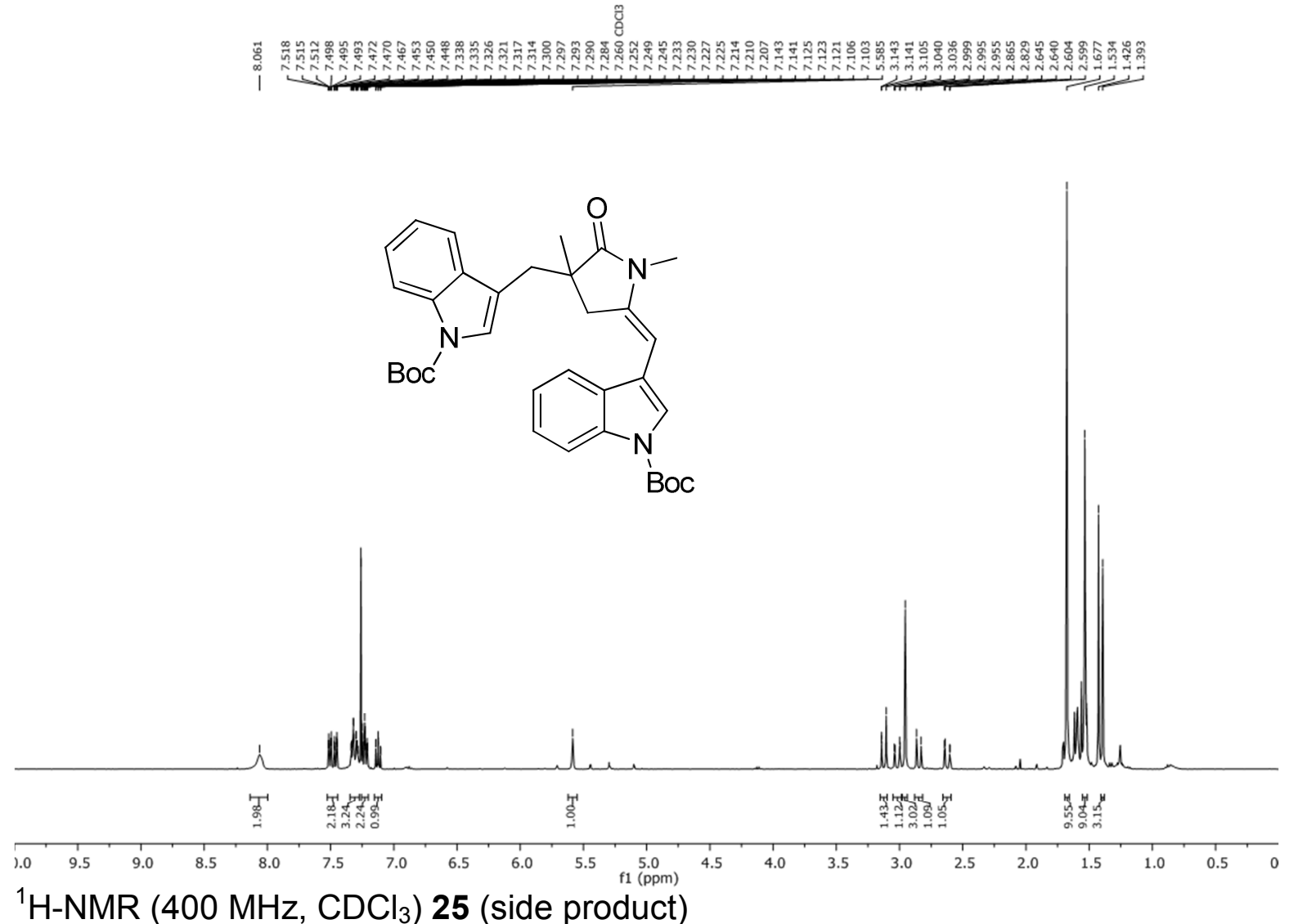

${ }^{1} \mathrm{H}-\mathrm{NMR}\left(400 \mathrm{MHz}, \mathrm{CDCl}_{3}\right) 25$ (side product)

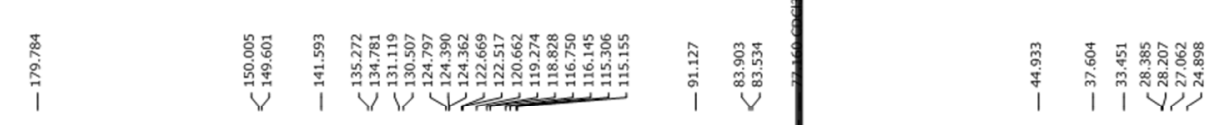<smiles>CN1C(=O)C(C)(Cc2cn(C(=O)OC(C)(C)C)c3ccccc23)C/C1=C\c1cn(C(=O)OC(C)(C)C)c2ccccc12</smiles>

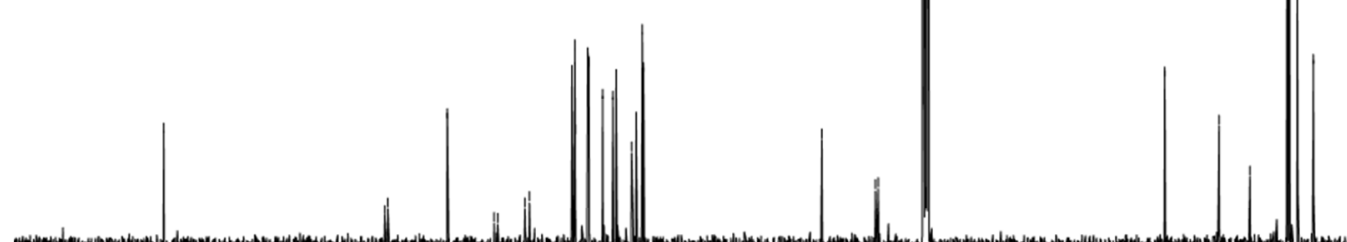

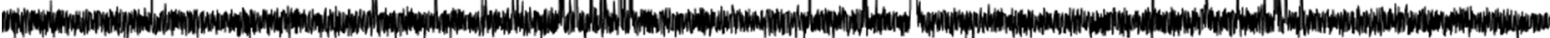

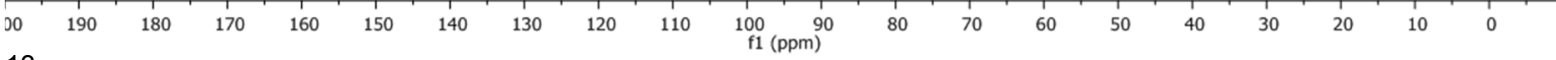

${ }^{13} \mathrm{C} \mathrm{NMR}\left(100.6 \mathrm{MHz}, \mathrm{CDCl}_{3}\right) 25$ (side product) 


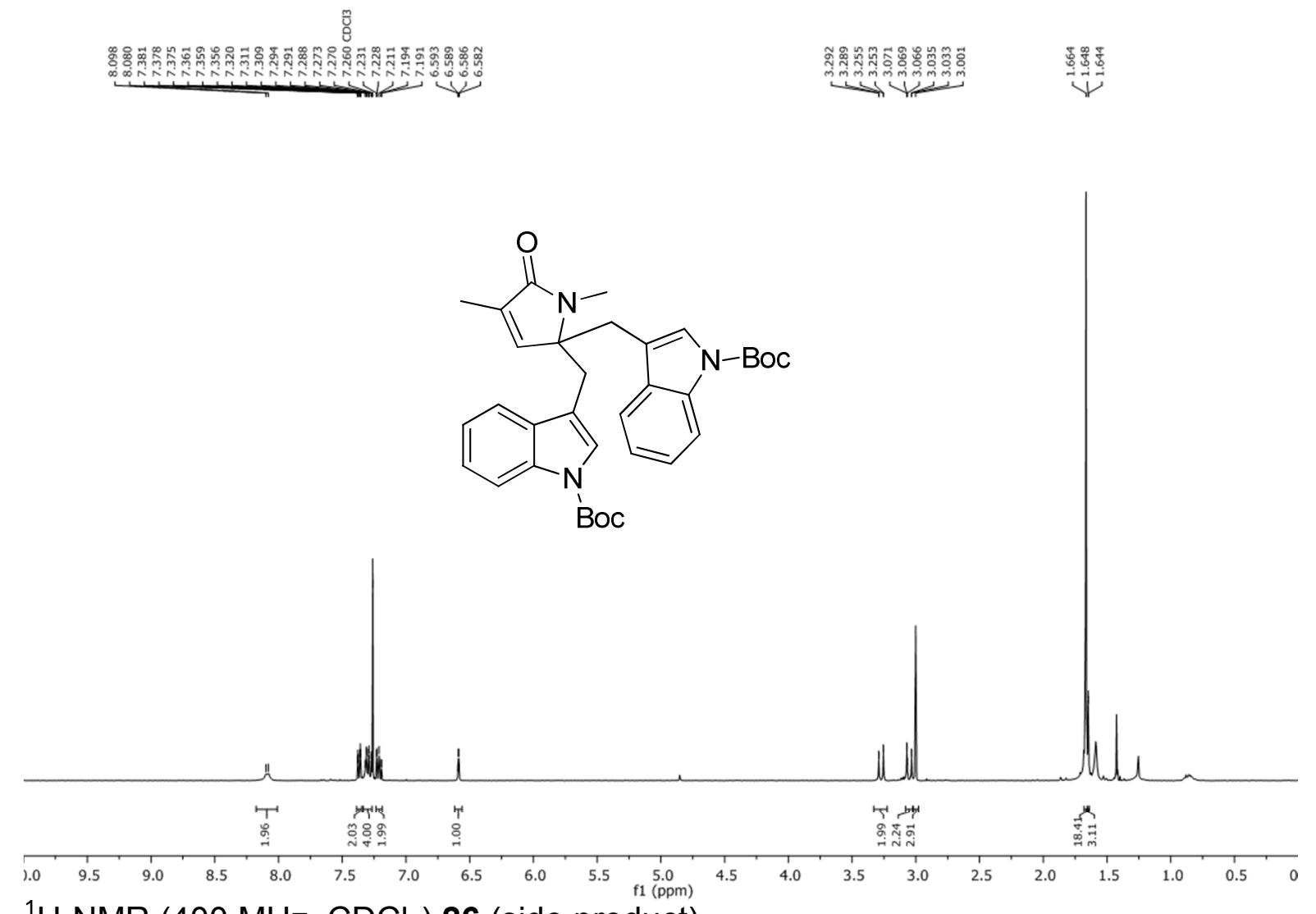

'H-NMR (400 MHz, $\left.\mathrm{CDCl}_{3}\right) 26$ (side product)
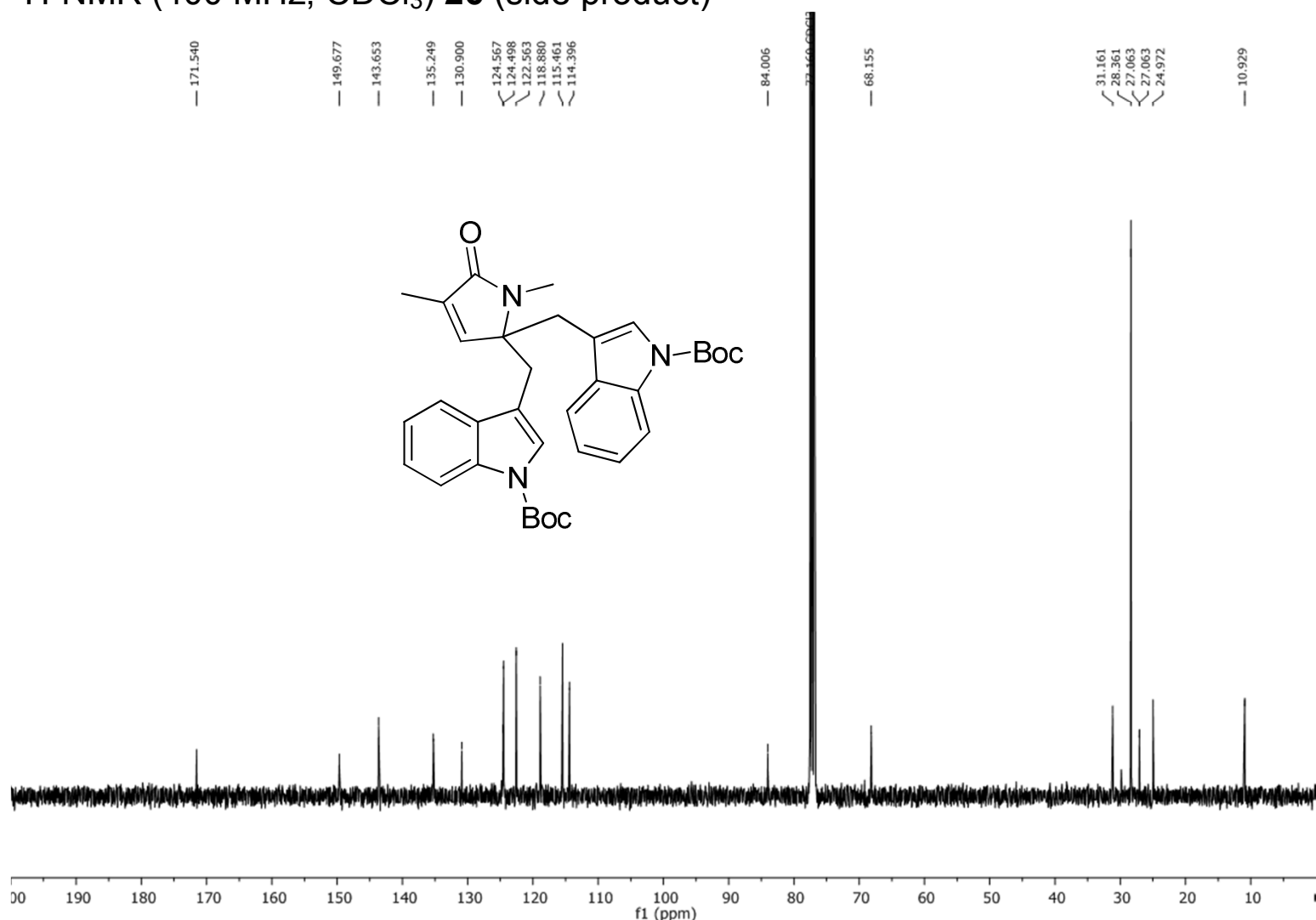

$\left.{ }^{13} \mathrm{C} \mathrm{NMR} \mathrm{(100.6} \mathrm{MHz,} \mathrm{CDCl}_{3}\right) 26$ (side product) 

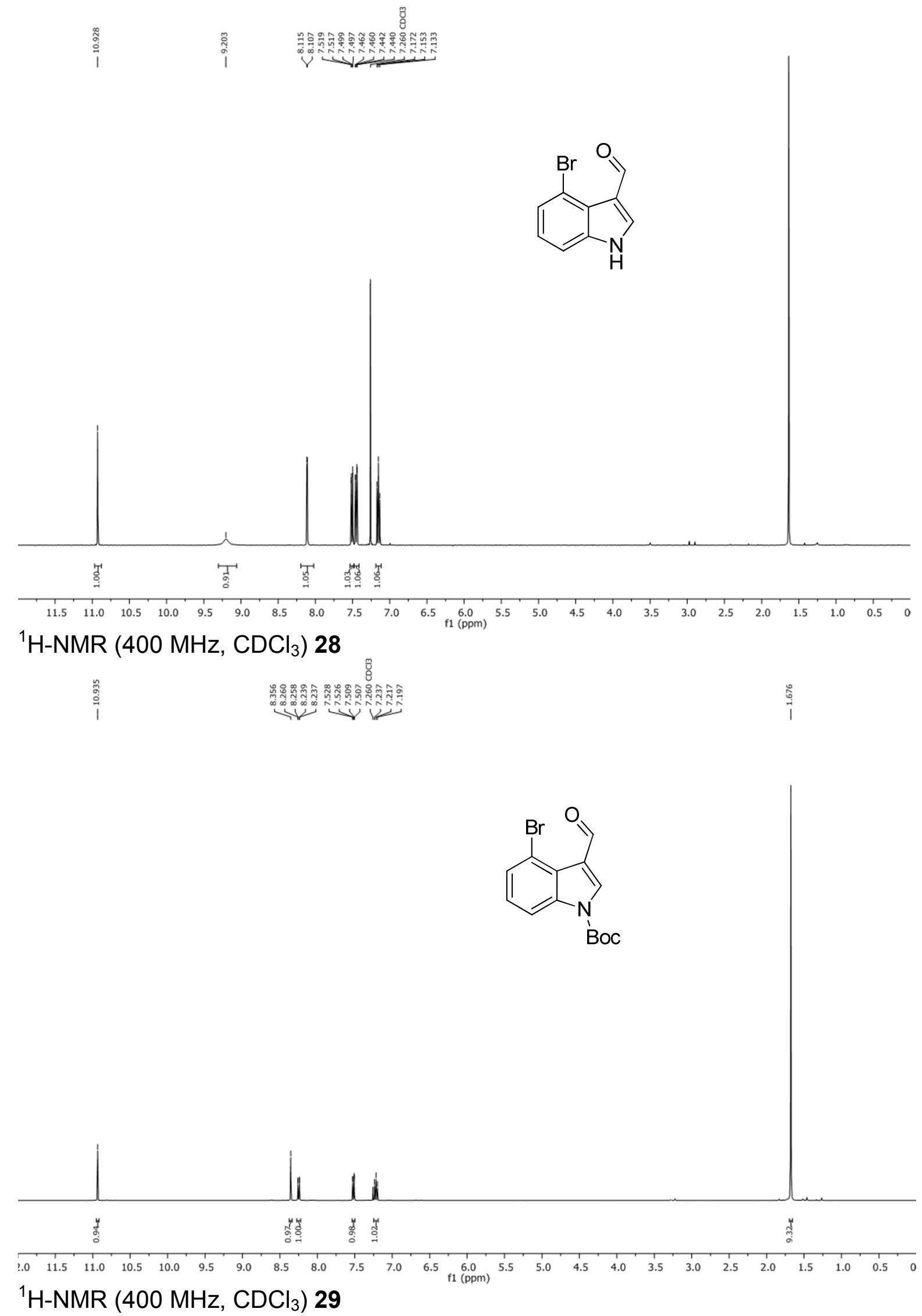

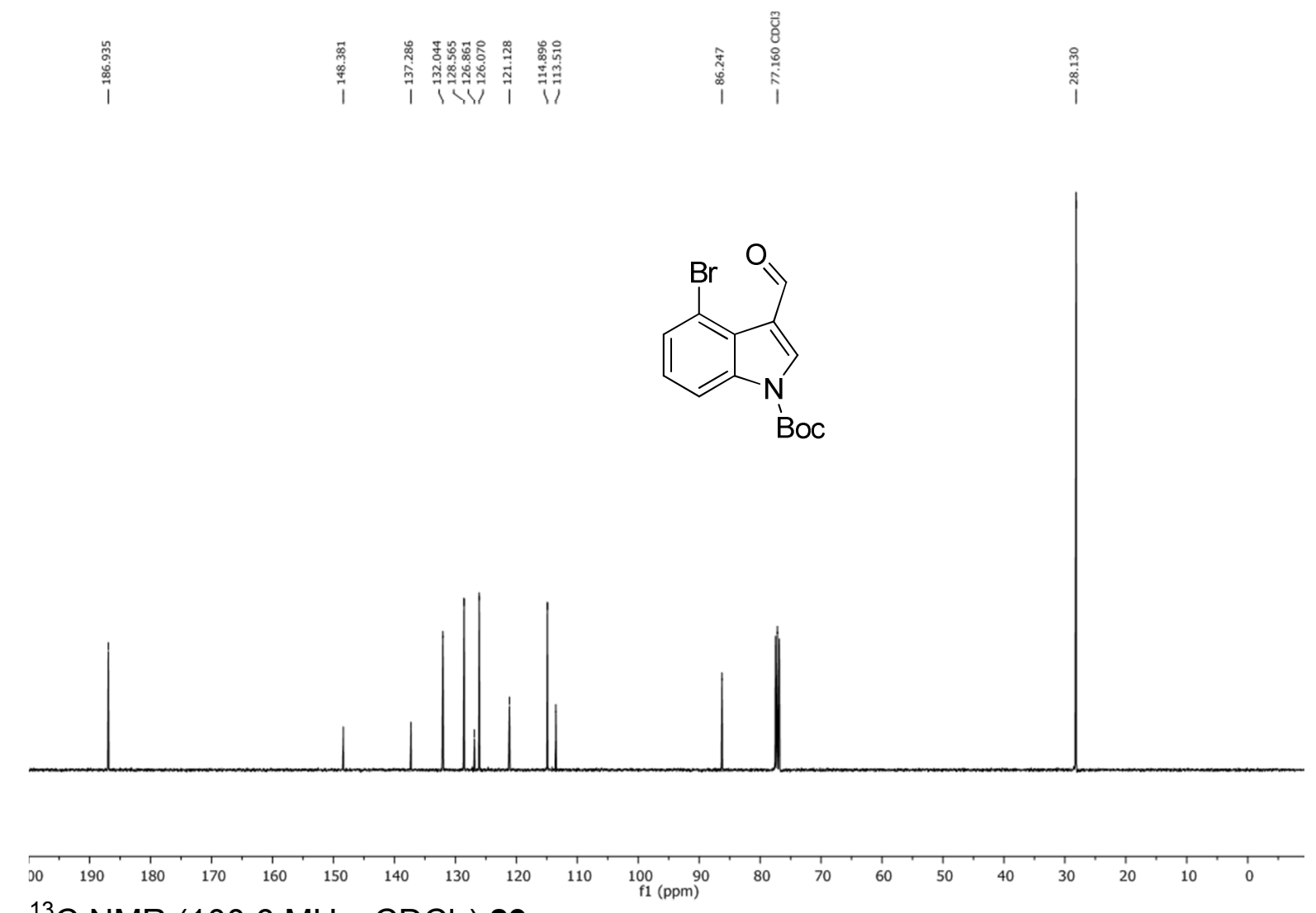

${ }^{13} \mathrm{C}$ NMR (100.6 MHz, $\left.\mathrm{CDCl}_{3}\right) 29$
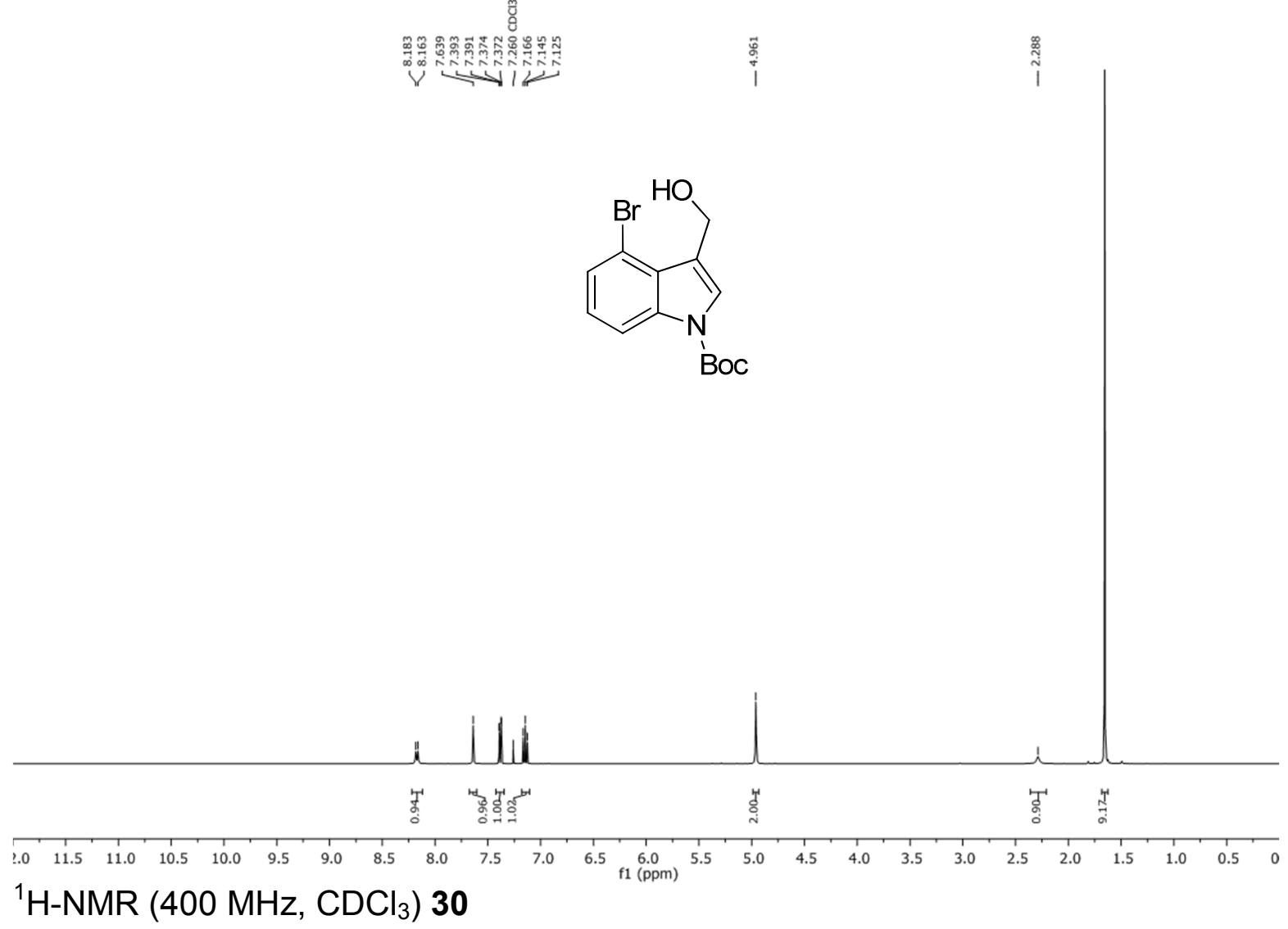

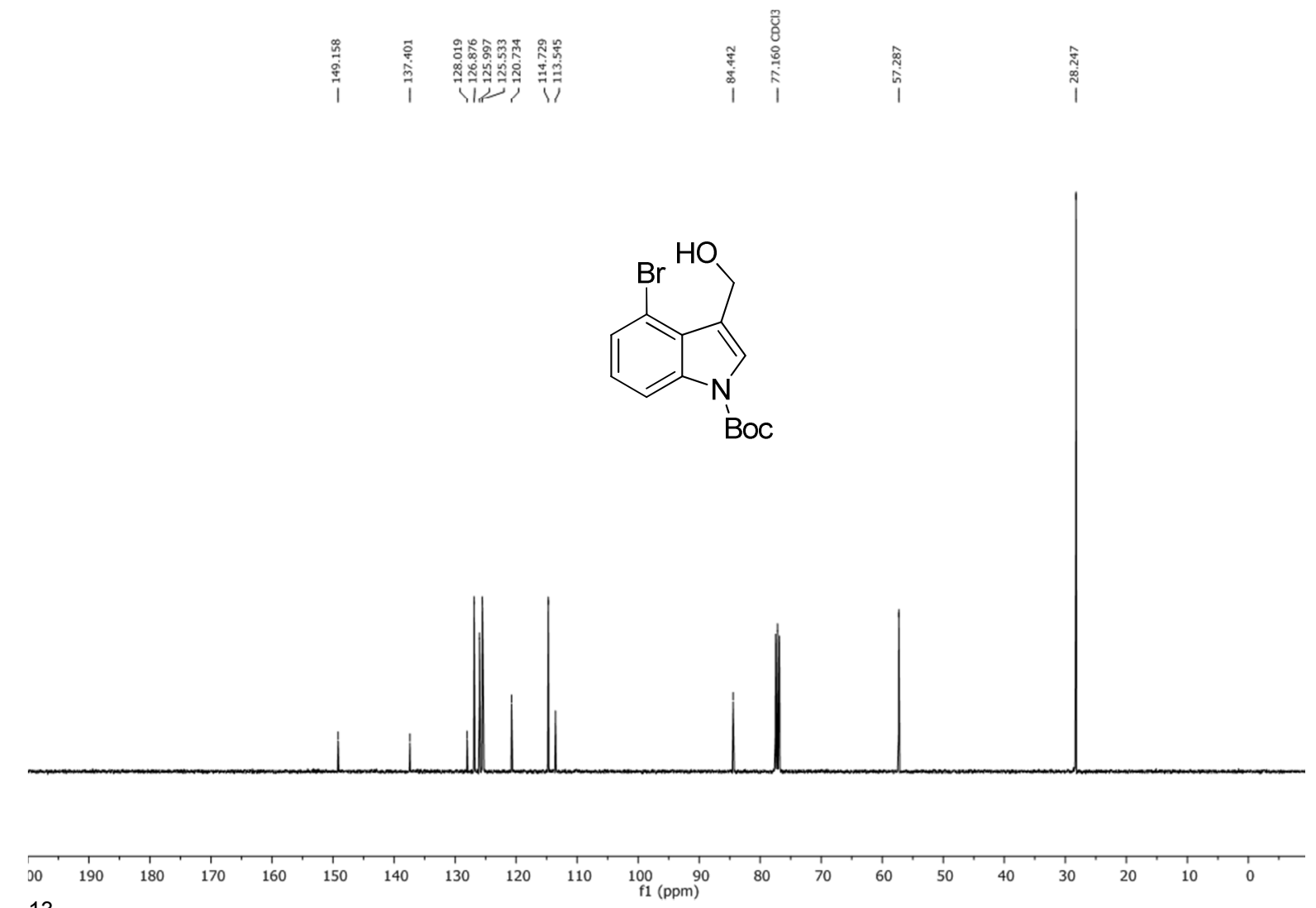

${ }^{13} \mathrm{C}$ NMR (100.6 MHz, $\left.\mathrm{CDCl}_{3}\right) 30$
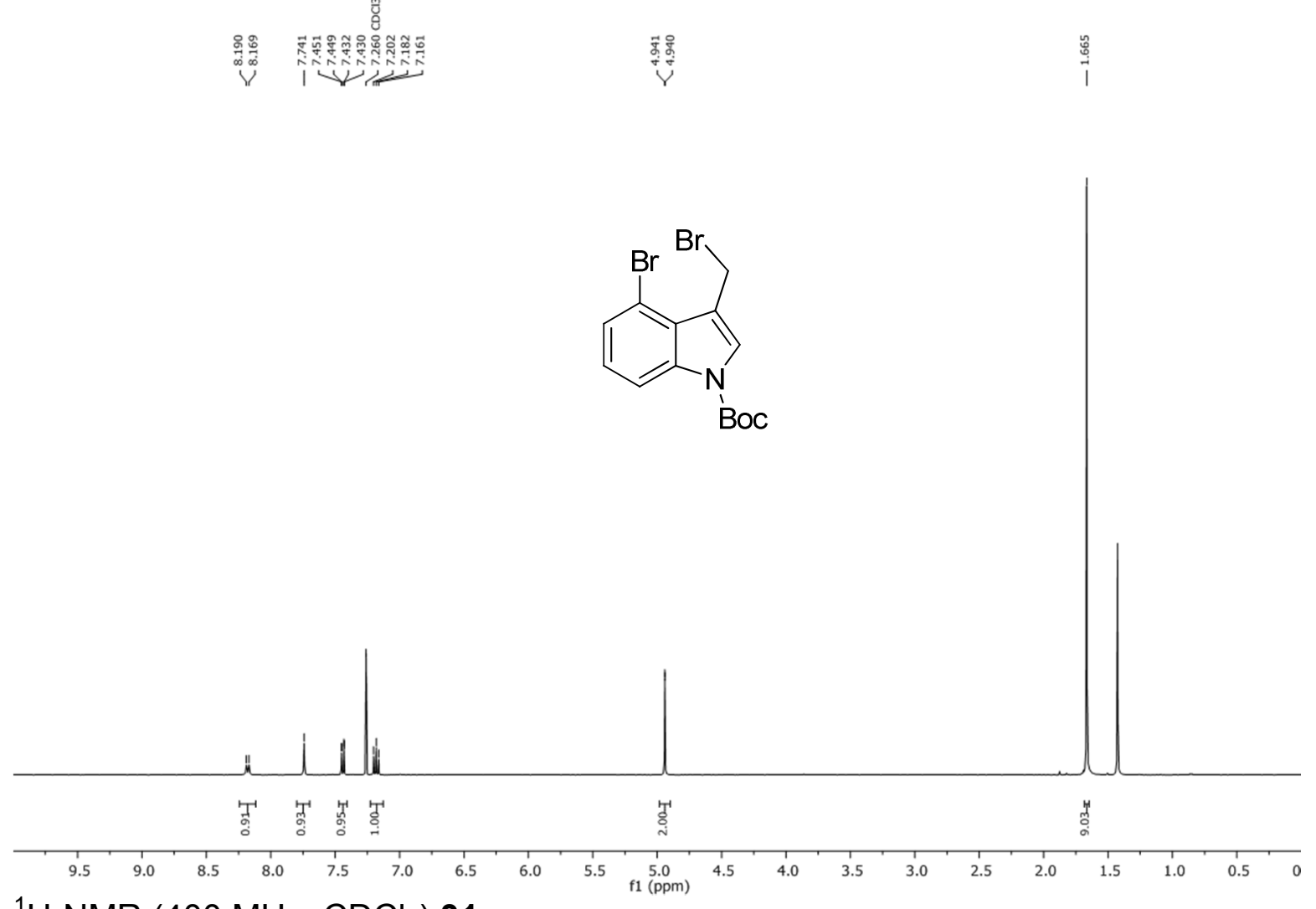

${ }^{1} \mathrm{H}-\mathrm{NMR}\left(400 \mathrm{MHz}, \mathrm{CDCl}_{3}\right) 31$ 

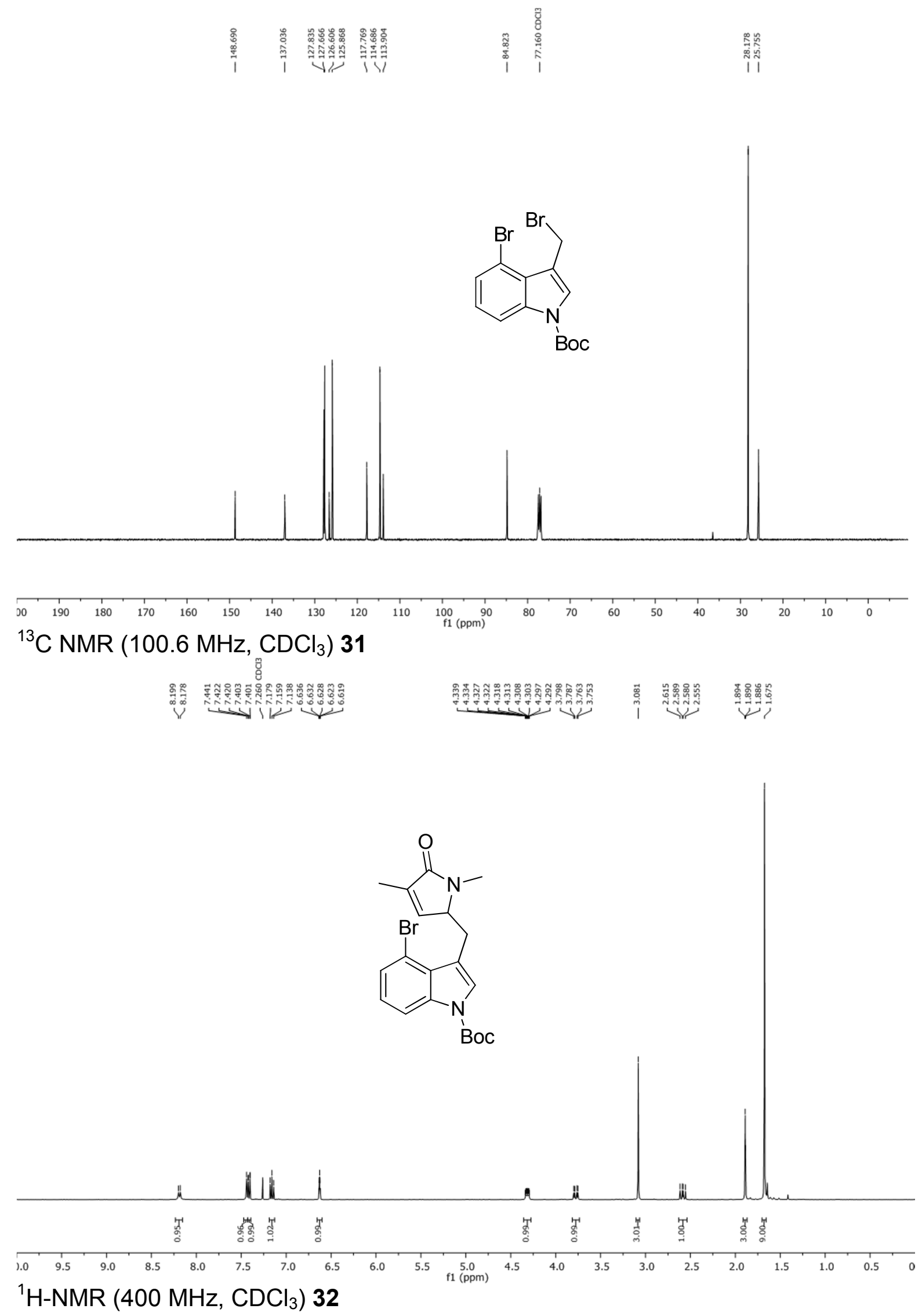


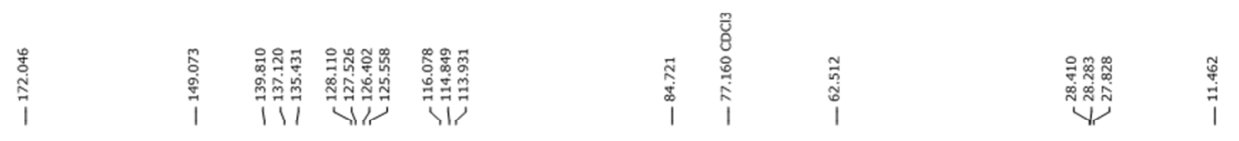<smiles>CC1=CC(Cc2cn(C(=O)OC(C)(C)C)c3cccc(Br)c23)N(C)C1=O</smiles>
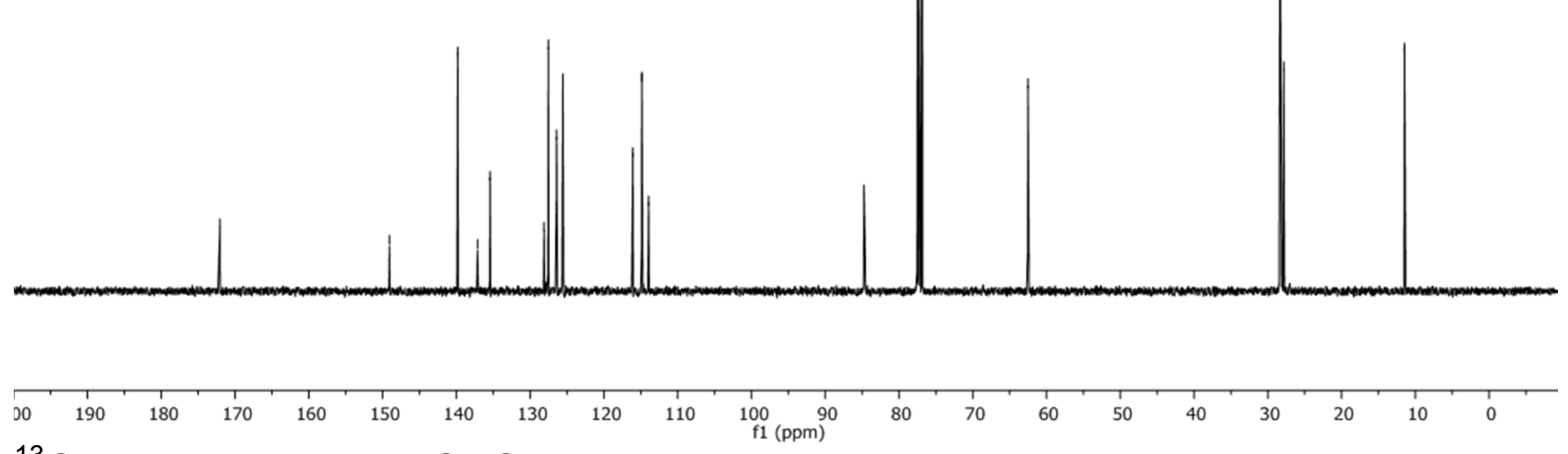

${ }^{13} \mathrm{C}$ NMR $\left(100.6 \mathrm{MHz}, \mathrm{CDCl}_{3}\right) 32$

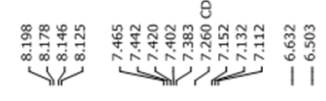

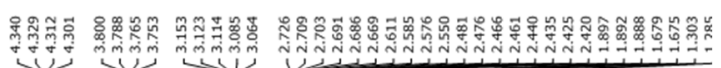<smiles>CC1C/C(=C\c2cn(C(=O)OC(C)(C)C)c3cccc(Br)c23)N(C)C1=O</smiles><smiles>CC(=O)n1cc(CC2C=C(C)C(=O)N2C)c2c(Br)cccc21</smiles>

$1: 0.7$

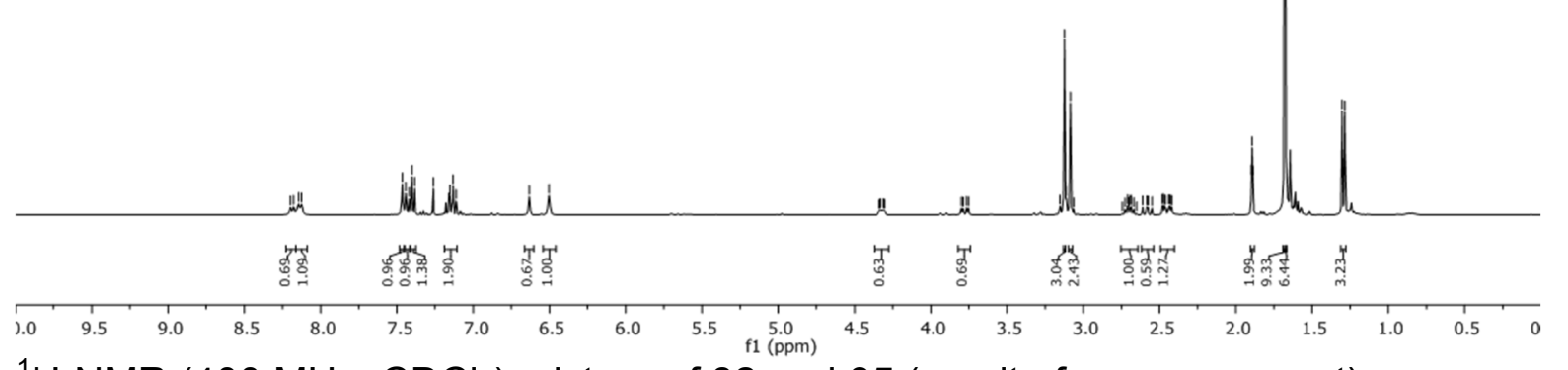

${ }^{1} \mathrm{H}-\mathrm{NMR}\left(400 \mathrm{MHz}, \mathrm{CDCl}_{3}\right)$ mixture of $\mathbf{3 2}$ and $\mathbf{3 5}$ (result of rearrangement) 

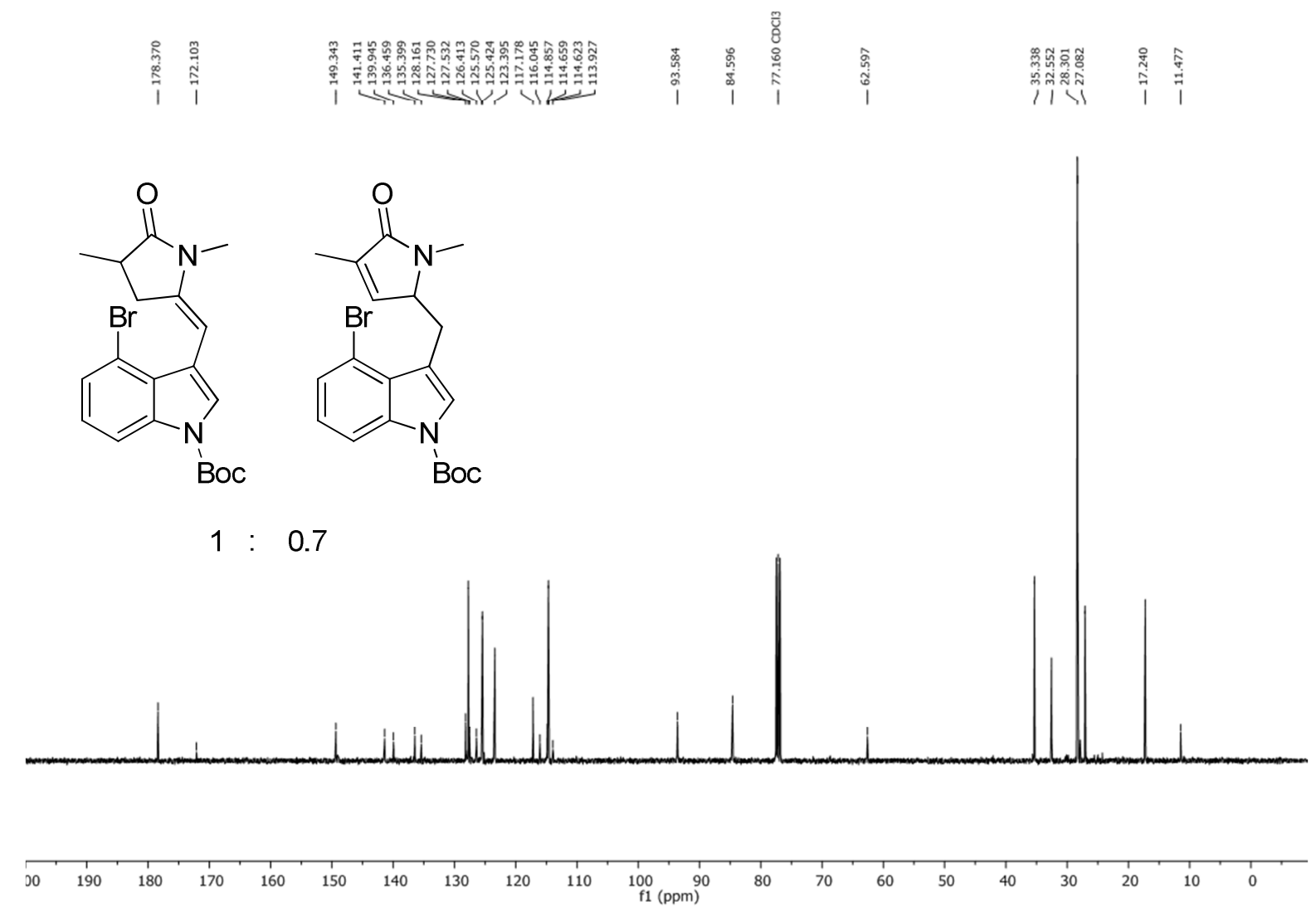

${ }^{13} \mathrm{C}$ NMR (100.6 MHz, $\mathrm{CDCl}_{3}$ ) mixture of 32 and 35 (result of rearrangement)

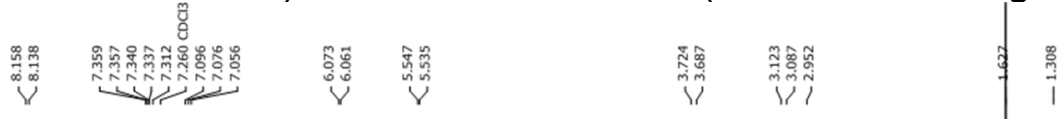<smiles>CN1C=CC(C)(Cc2cn(C(=O)OC(C)(C)C)c3cccc(Br)c23)C1=O</smiles>

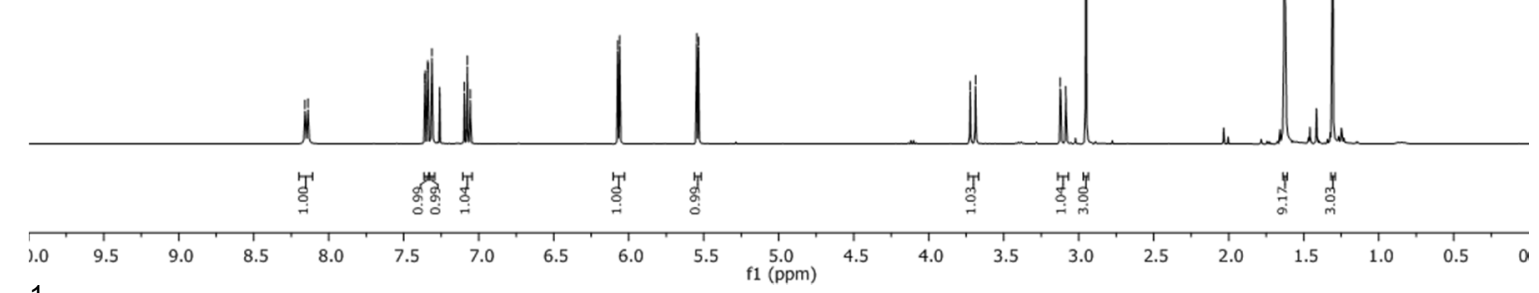

${ }^{1} \mathrm{H}-\mathrm{NMR}\left(400 \mathrm{MHz}, \mathrm{CDCl}_{3}\right) 33$ 

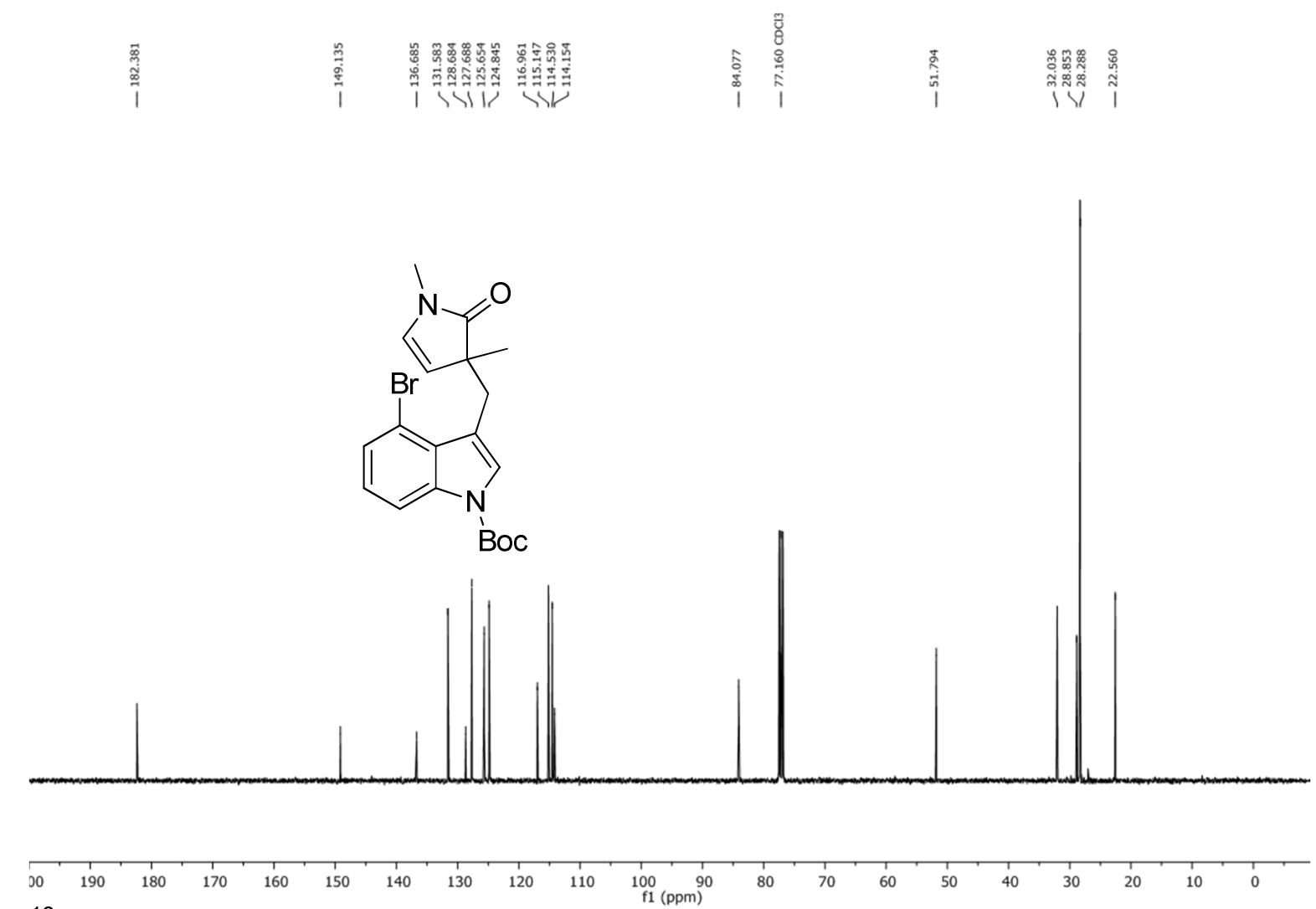

${ }^{13} \mathrm{C}$ NMR (100.6 MHz, $\left.\mathrm{CDCl}_{3}\right) 33$
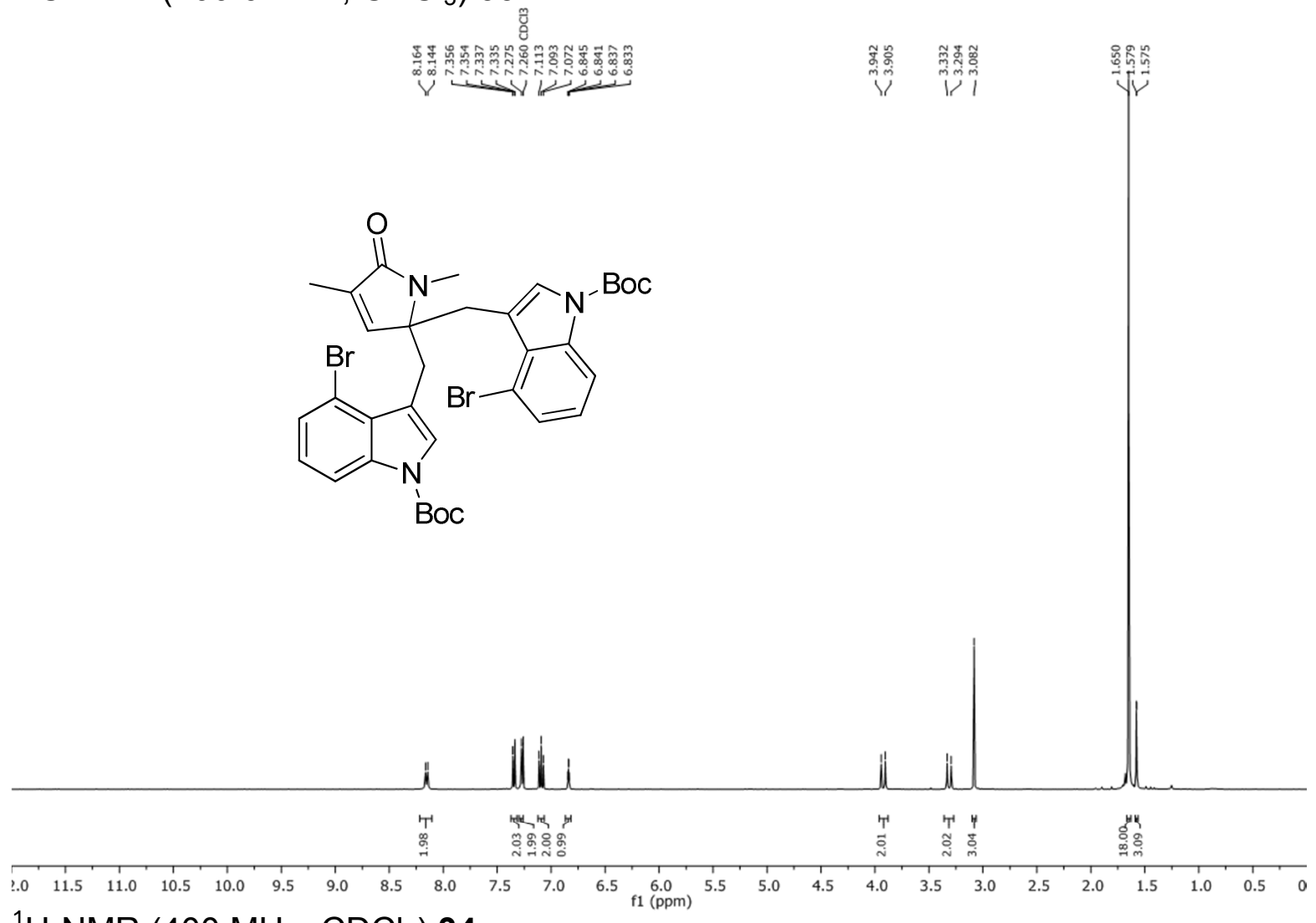

${ }^{1} \mathrm{H}-\mathrm{NMR}\left(400 \mathrm{MHz}, \mathrm{CDCl}_{3}\right) 34$ 

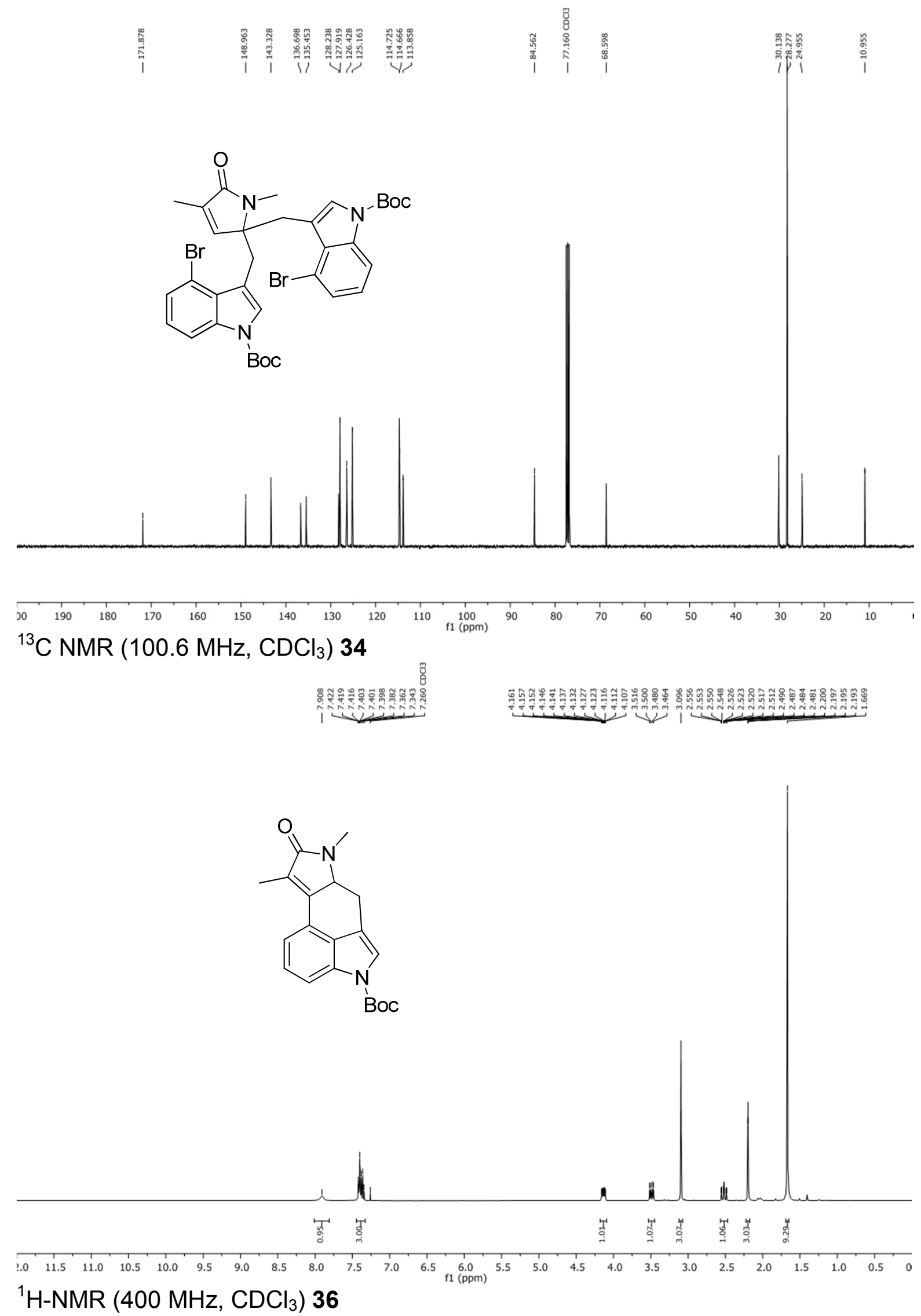

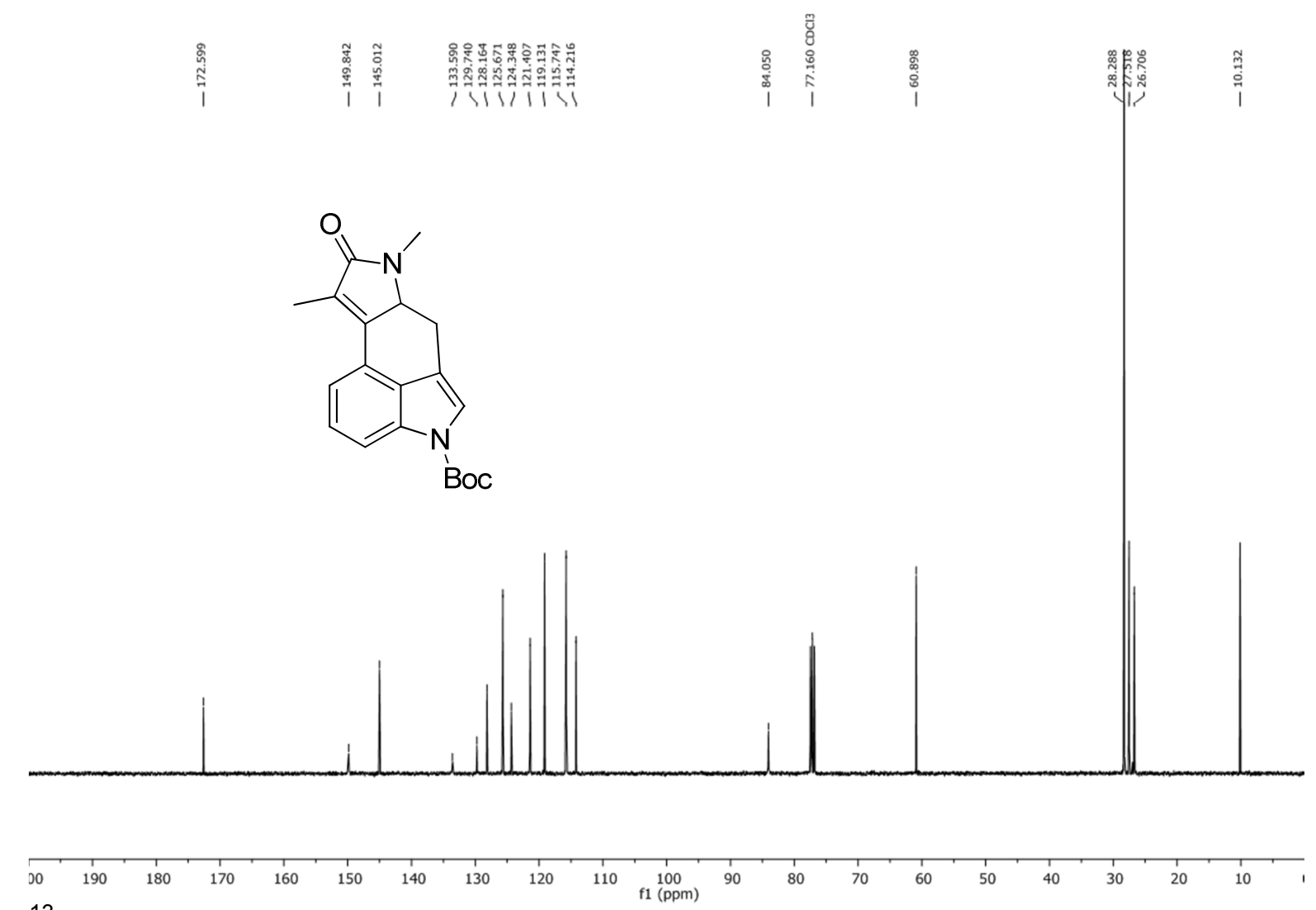

${ }^{13} \mathrm{C}$ NMR (100.6 MHz, $\left.\mathrm{CDCl}_{3}\right) 36$
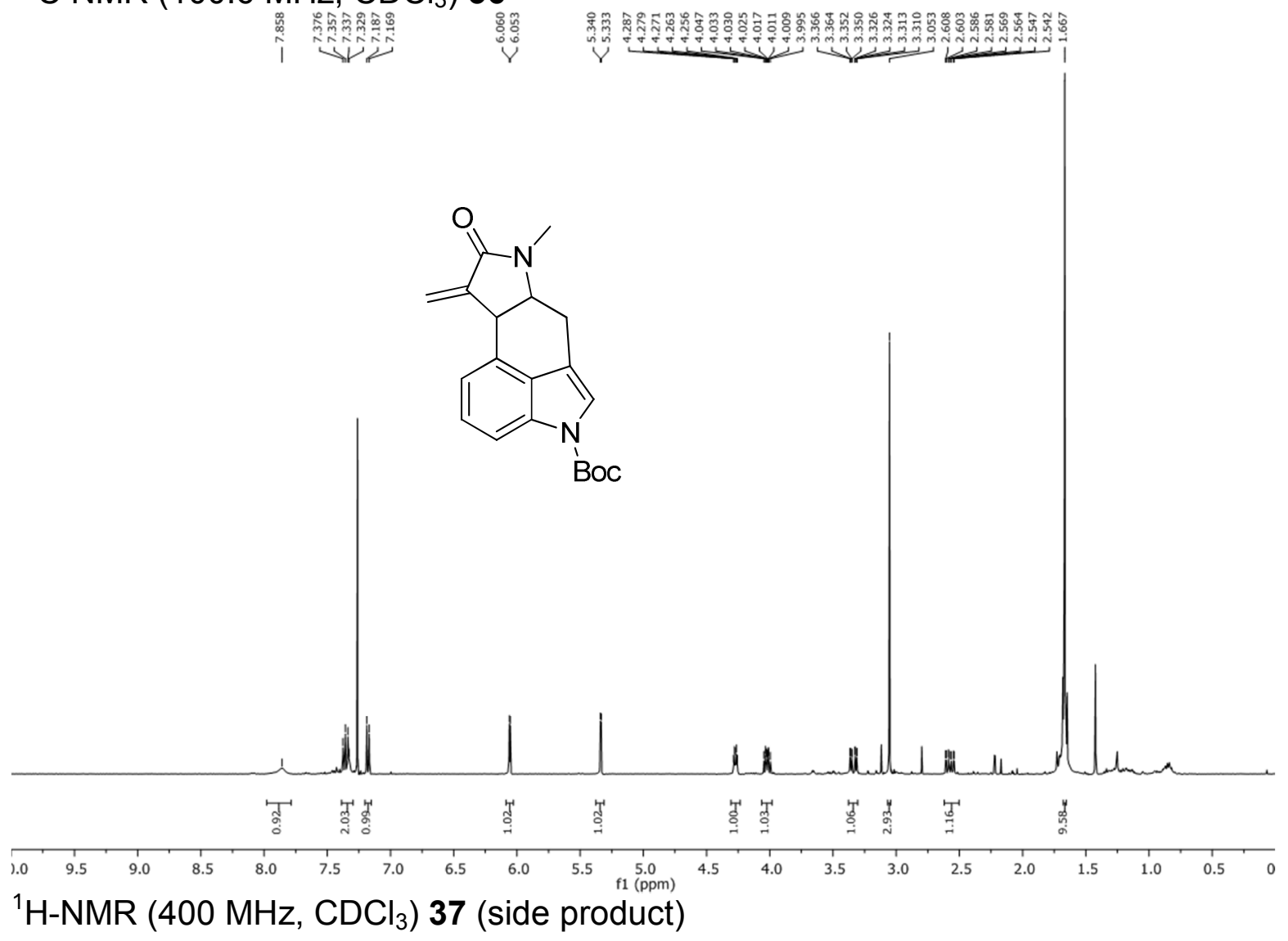

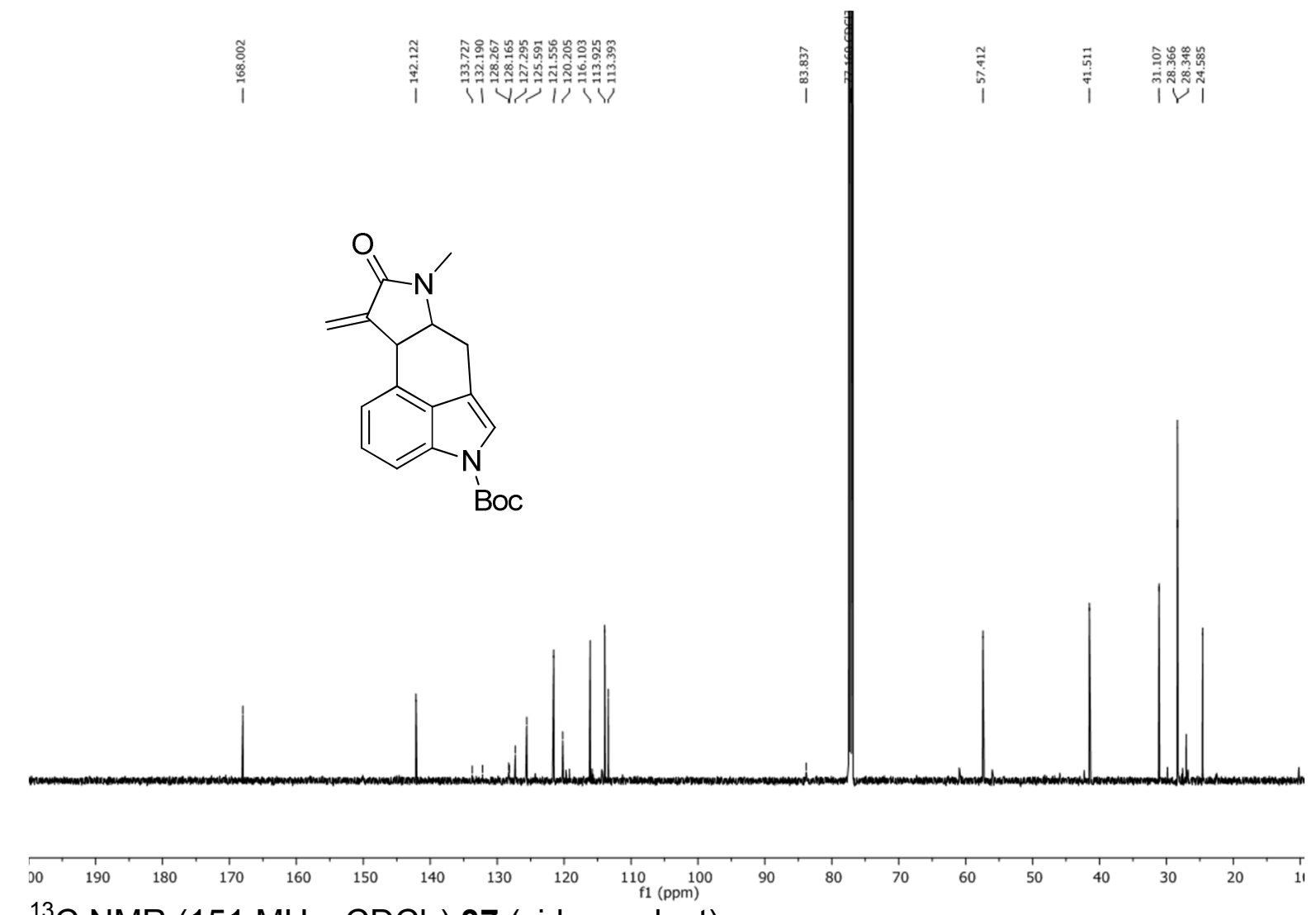

${ }^{13} \mathrm{C}$ NMR (151 MHz, $\mathrm{CDCl}_{3}$ ) 37 (side product)

范
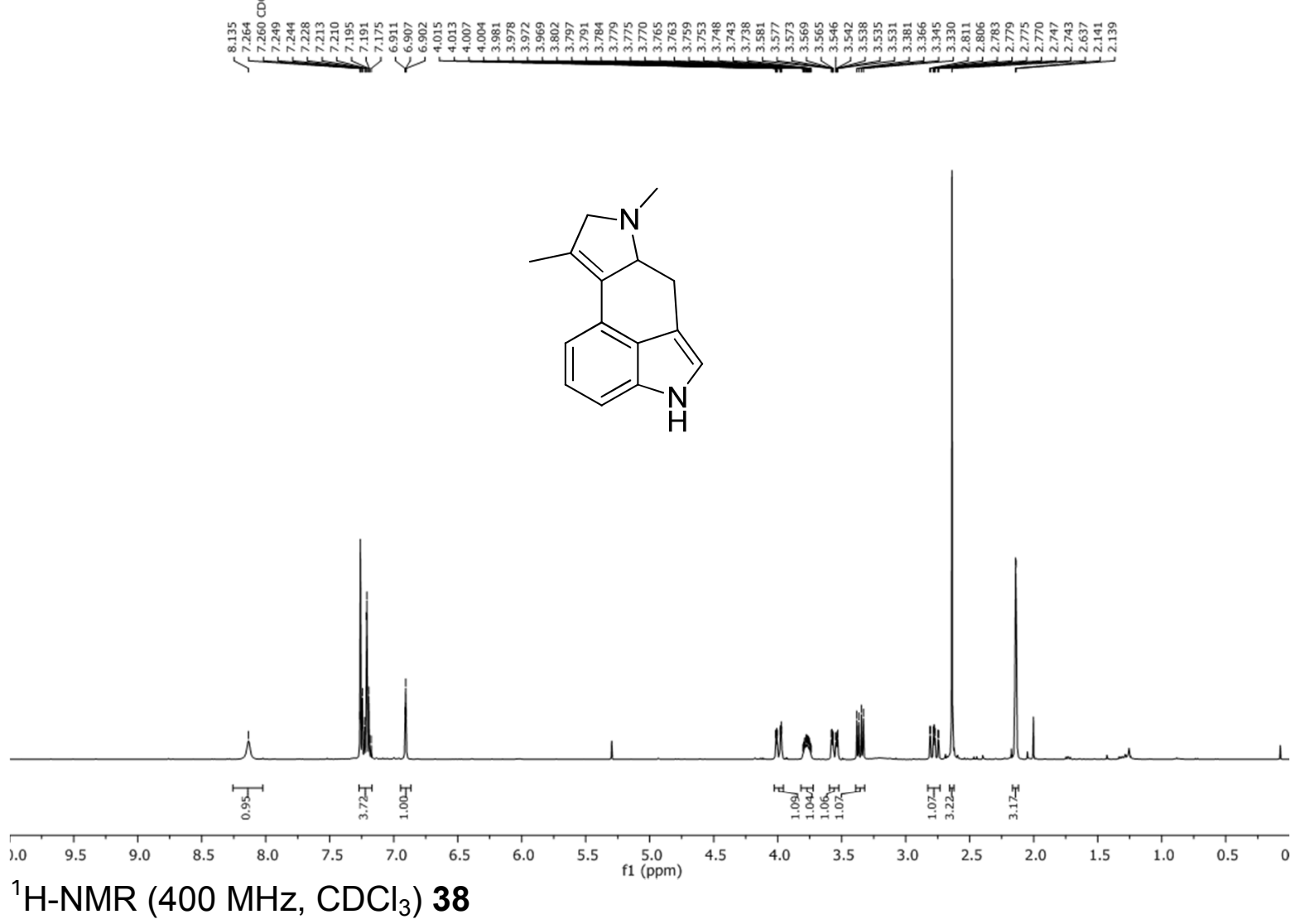

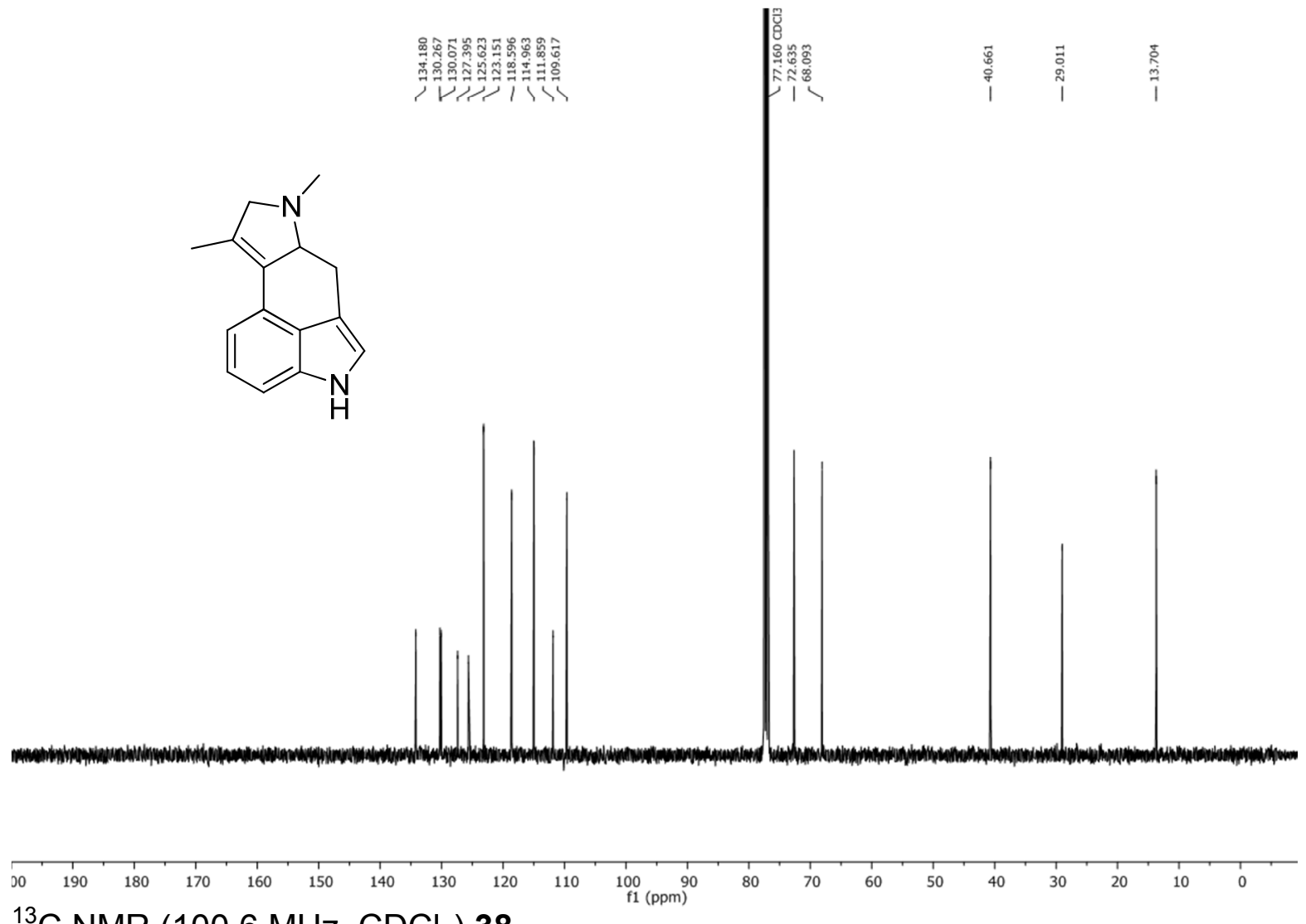

${ }^{13} \mathrm{C}$ NMR $\left(100.6 \mathrm{MHz}, \mathrm{CDCl}_{3}\right) 38$ 